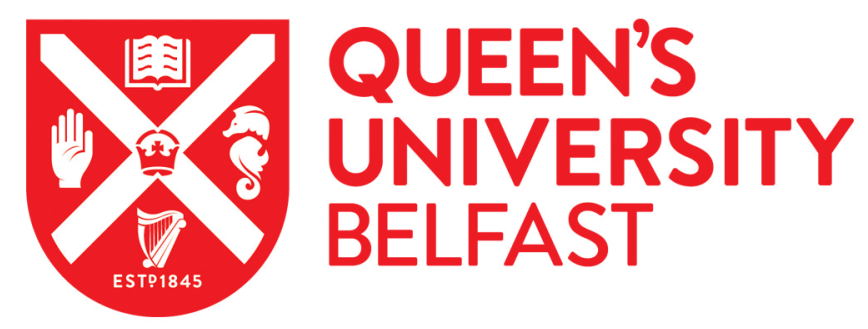

\title{
Use of carbon-based composites to enhance performance of TiO2 for the simultaneous removal of nitrates and organics from aqueous environments
}

Adamu, H., Shand, M., Taylor, R. S. F., Manyar, H. G., \& Anderson, J. A. (2018). Use of carbon-based composites to enhance performance of $\mathrm{TiO} 2$ for the simultaneous removal of nitrates and organics from aqueous environments. Environmental science and pollution research international.

https://doi.org/10.1007/s11356-018-3120-x

\section{Published in:}

Environmental science and pollution research international

\section{Document Version:}

Peer reviewed version

Queen's University Belfast - Research Portal:

Link to publication record in Queen's University Belfast Research Portal

\author{
Publisher rights \\ (c) 2018 Springer-Verlag GmbH Germany, part of Springer Nature. This work is made available online in accordance with the publisher's \\ policies. Please refer to any applicable terms of use of the publisher.
}

\section{General rights}

Copyright for the publications made accessible via the Queen's University Belfast Research Portal is retained by the author(s) and / or other copyright owners and it is a condition of accessing these publications that users recognise and abide by the legal requirements associated with these rights.

\section{Take down policy}

The Research Portal is Queen's institutional repository that provides access to Queen's research output. Every effort has been made to ensure that content in the Research Portal does not infringe any person's rights, or applicable UK laws. If you discover content in the Research Portal that you believe breaches copyright or violates any law, please contact openaccess@qub.ac.uk. 


\title{
Use of Carbon Based Composites to Enhance Performance of $\mathrm{TiO}_{2}$ for the Simultaneous Removal of Nitrates and Organics from Aqueous Environments.
}

\author{
Haruna Adamu ${ }^{\mathrm{a}, \mathrm{b}, \mathrm{c} *}$, Mikaela Shand ${ }^{\mathrm{a}}$, Rebecca S. F. Taylor ${ }^{\mathrm{d}}$, Haresh G. Manyar ${ }^{\mathrm{e}}$ James A. \\ Anderson $^{\mathrm{a}}$

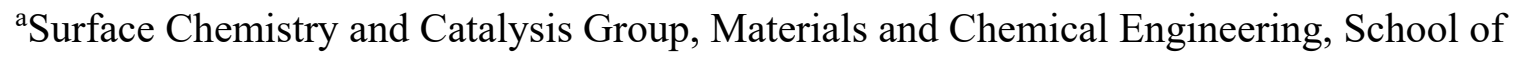 \\ Engineering, University of Aberdeen, AB24 3UE, UK \\ ${ }^{b}$ Department of Environmental Management Technology, Abubakar Tafawa Balewa \\ University, Bauchi-Nigeria

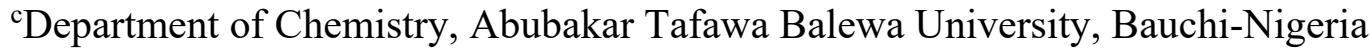 \\ ${ }^{\mathrm{d} S c h o o l}$ of Chemical Engineering and Analytical Science, The University of Manchester, \\ The Mill,Sackville Street, Manchester, M13 9PL, UK \\ eCenTACat, School of Chemistry and Chemical Engineering, Queen's University, Belfast, \\ David Keir Building, Stranmillis Road, Belfast, BT9 5AG, UK \\ * Correspondent author's Email: hadamu2@atbu.edu.ng
}

\begin{abstract}
The simultaneous photocatalytic removal of nitrate from aqueous environment in presence organic hole scavenger using $\mathrm{TiO}_{2}$ has long been explored. However, the use of unmodified $\mathrm{TiO}_{2}$ in such reaction resulted in non-performance or release of significant amount of undesirable reaction products in the process, a problem that triggered surface modification of $\mathrm{TiO}_{2}$ for enhanced photocatalytic performance. Previous studies focused on decreasing rate of charge carrier recombination and absorption of light in the visible region. Yet, increasing active sites and adsorption capacity by combining $\mathrm{TiO}_{2}$ with a high surface area adsorbent such as activated carbon (AC) remains unexploited. This study reports the potential of such modification in simultaneous removal of nitrates and oxalic acid in aqueous environment. The adsorptive behaviour of nitrate and oxalic acid on $\mathrm{TiO}_{2}$ and $\mathrm{TiO}_{2} / \mathrm{AC}$ composites were studied. The Langmuir adsorption coefficient for nitrate was 4 times greater than that of oxalic acid. However, the amount of oxalic acid adsorbed was about 10 times greater than the amount of nitrate taken up. Despite this advantage, the materials did not appear to produce more active photocatalysts for the simultaneous degradation of nitrate and oxalic acid. The photocatalytic activity of $\mathrm{TiO}_{2}$ and its carbon-based composites was improved by combination with $\mathrm{Cu}_{2} \mathrm{O}$ particles. Consequently, $2.5 \mathrm{Cu}_{2} \mathrm{O} / \mathrm{TiO}_{2}$ exhibited the maximum photocatalytic performance with 57.6 and $99.8 \%$ removal of nitrate and oxalic acid, respectively, while selectivity stood at 45.7, 12.4 and $41.9 \%$ for $\mathrm{NH}_{4}{ }^{+}, \mathrm{NO}_{2}{ }^{-}$and $\mathrm{N}_{2}$, respectively. For the carbon based, 2.5 $\mathrm{Cu}_{2} \mathrm{O} / \mathrm{TiO}_{2}-20 \mathrm{AC}$ showed removal of $12.7 \%$ nitrate and $80.3 \%$ oxalic acid and achieved 21.6, 0 and $78.4 \%$ selectivity for $\mathrm{NH}_{4}^{+}, \mathrm{NO}_{2}{ }^{-}$and $\mathrm{N}_{2}$, respectively. Using the optimal AC loading $(20 \mathrm{wt} \%)$ resulted in significant decrease in the selectivity for $\mathrm{NH}_{4}{ }^{+}$with no formation of $\mathrm{NO}_{2}{ }^{-}$ , which unveils that selectivity for $\mathrm{N}_{2}$ and low/no selectivity for undesirable products can be manipulated by controlling the rate of consumption of oxalic acid. In contract, no nitrate reduction was observed with $\mathrm{Cu}_{2} \mathrm{O}$ promoted $\mathrm{TiO}_{2}-\mathrm{T}$ and its $\mathrm{TiO}_{2}-(\mathrm{T})-20 \mathrm{AC}$, which may be
\end{abstract}


connected to amorphous nature of $\mathrm{TiO}_{2}-\mathrm{T}$ and perhaps served as charge carrier trapping sites that impeded activity.

Keywords: Nitrate, oxalic acid, titania, activated carbon, composites, photocatalysis.

\section{Introduction}

Photocatalysis using semiconductor oxides offers a potential solution to the treatment of contaminated waters. By far most of studies focus on the removal of organic pollutants using dye molecules or phenols to represent classes of pollutants which might be treated. These exploit the oxidation potential of the holes created in the solid following exposure to radiation of energy greater than the band gap. However, this often ignores the potential to degrade contaminants by exploiting the reduction potential of the simultaneously created electrons in the conduction band. The simultaneous removal of nitrate and organic from aqueous environment is one such exception (Anderson, 2012). Potential improvements to current photocatalyst for this reaction have been discussed and described (Shand and Anderson, 2013). In addition to minimizing the rate of charge carrier recombination and enhanced absorption of light in the visible region, other modifications might involve increasing site access, increasing the proportion of active sites and increasing the adsorption capacity (because $\mathrm{TiO}_{2}$ with small surface area is associated with poor adsorption of pollutants) (Shand and Anderson, 2013; Yang et al., 2017). One potential methodology to explore the later would be to combine $\mathrm{TiO}_{2}$ with a high surface area adsorbent such as an activated carbon (Matos et al., 1998).

In recent years, heterogeneous simultaneous photocatalytic degradation of aqueous inorganic and organic pollutants by the synergic oxidation-reduction capacity of $\mathrm{TiO}_{2}$ has been developed and has emerged as a promising advanced green remediation technology for decontamination of co-contamination of drinking water sources. Nitrate has appeared as one of the most prevalent contaminants of surface and ground water, which originates from intensive agricultural activities, poor urban sewage management and waste disposal, as well as industrial effluents (Wakida and Lerner, 2005) and thus, considered as a serious global problem (Hirayama and Kamiya, 2014). Moreover, organic pollutants are incessantly discharge into aqueous environments from different industries including textiles, plastic, refinery, petrochemical, pharmaceutical, agrochemical as well as pulp and paper which could co-exist with nitrate (Beltrán et al., 2005; L. Li et al., 2010; Saeed et al., 2013). It has been explored that $\mathrm{TiO}_{2}$ either in its pristine or metallic coupled system has potential in simultaneous remediation of nitrates and organics that co-exist in aqueous environment (Anderson and 
Fernandez-Garcia, 2009). However, $\mathrm{TiO}_{2}$ surface photocatalytic oxidation-reduction reaction is hampered by the inherent low surface area (Yang et al., 2017), which has usually resulted in low activity of photo-reduction of $\mathrm{NO}_{3}{ }^{-}$to $\mathrm{N}_{2}$ gas in presence of organic hole scavenger and thus, the results so far reported are usually lower and far from the looked-for values (Anderson, 2012). Consequently, this has prompted to explore the potential of immobilised photocatalyst supporting systems, upon which the particles of $\mathrm{TiO}_{2}$ are to be mounted on porous carbonaceous materials, such as activated carbon to result in formation of $\mathrm{TiO}_{2} / \mathrm{AC}$ composite, aiming to increase accessibility of sites and adsorption capacity (Shand and Anderson, 2013). This in effect could result in adsorption-photocatalytic redox hybrid system, which brings about new porous and adsorption sites that could highly concentrate embattled pollutants around the light harvesting centres of $\mathrm{TiO}_{2}$ particles and consequently be photodegradation thereon rapidly because of their proximity to photocatalytic sites. This can be supported with an assertion that a composite system containing appreciable large surface area material can scaffold $\mathrm{TiO}_{2}$ nanoparticles (Pinheiro et al., 2017), which such can improve surface contact between pollutants and $\mathrm{TiO}_{2}$ as well as mechanical stability of $\mathrm{TiO}_{2}$ in aqueous environment.

Research on interface-induced effect and large specific surface area of heteronanostructures are attracting much attentions due to applications in photocatalysis (He, 2016). One area of this aspect is the application of titania-activated carbon $\left(\mathrm{TiO}_{2} / \mathrm{AC}\right)$ composites in water and wastewater treatment technologies for enhanced removal of pollutants, which has for long been discussed (Andreina, 2010; Gao et al., 2011; Lim et al., 2011; Matos et al., 1998). Results from the literature indicated that the photocatalytic performance of $\mathrm{TiO}_{2} / \mathrm{AC}$ composites has been found to be more versatile and effective in the removal of aqueous pollutants, particularly organics, compared to pure $\mathrm{TiO}_{2}$ and physically mixed $\mathrm{TiO}_{2}-\mathrm{AC}$ (Matos et al., 1998). The outstanding performance of the $\mathrm{TiO}_{2} / \mathrm{AC}$ composites has been attributed to the synergetic cooperation of $\mathrm{AC}$ through its ability to concentrate aqueous organic pollutants around the surface of $\mathrm{TiO}_{2}$, which in turn increased proximity of pollutants to the surface of $\mathrm{TiO}_{2}$ that led to rapid degradation (Matos et al., 2001; Matos et al., 2007). Therefore, to test whether improvement in performance in the simultaneous photocatalytic removal of nitrate and oxalic acid might be attained by enhancing adsorption capacity, experiments were conducted using a number of $\mathrm{TiO}_{2} / \mathrm{AC}$ composites. 


\section{Materials and method}

\subsection{Materials}

All the chemicals used were of analytical grade. A commercially available titanium dioxide, Degussa P25 $\left(\mathrm{TiO}_{2}\right.$, Degussa-Aeroxide $\left.\geq 99.5 \%\right)$ was purchased in powdered form and used as received. Potassium nitrate $\left(\mathrm{KNO}_{3}, \geq 99 \%\right.$ Sigma-Aldrich ACS reagent) was used as the model nitrate source and pollutant. Oxalic acid dehydrates $\left(\mathrm{H}_{2} \mathrm{C}_{2} \mathrm{O}_{4} * 2 \mathrm{H}_{2} \mathrm{O}, 99 \% \geq\right.$ Sigma-Aldrich ACS reagent) was used as the model organic pollutant. Both oxalic acid and nitrate were constantly used as hole scavenger and electron acceptor, respectively, for the adsorption and photocatalytic tests. Copper (II) nitrate trihydrate $\left(\mathrm{Cu}\left(\mathrm{NO}_{3}\right)_{2} * 3 \mathrm{H}_{2} \mathrm{O} \geq 99.5 \%\right.$ analaR BDH chemical) also used as a source of copper. Nitrate and ammonium Spectroquant test kits were purchased from Merck and used as supplied.

Titanium tetraisopropoxide $\left(\mathrm{Ti}\left[\mathrm{OCH}\left(\mathrm{CH}_{3}\right)_{2}\right]_{4} \geq 99 \%\right.$ Sigma-Aldrich ACS reagent), nitric acid $\left(\mathrm{HNO}_{3}, 70 \%\right.$ Fisher-Scientific) and sodium hydroxide $(\mathrm{NaOH}, \geq 99 \%$ SigmaAldrich ACS reagent) were the chemical used for the synthesis of home-made $\mathrm{TiO}_{2}$ photocatalyst and a commercially based activated carbon powder (Chemenviron carbon) was used for the formation of $\mathrm{TiO}_{2} / \mathrm{AC}$ composite photocatalysts. Distilled and ultra-pure deionised water (MilliQ, 18.2 M $\Omega-\mathrm{cm}$ ) were used where necessary throughout the study.

\subsection{Synthesis of $\mathrm{TiO}_{2} / \mathrm{AC}$ composites and pristine $\mathrm{TiO}_{2}$ photocatalysts}

Titania-activated carbon $\left(\mathrm{TiO}_{2} / \mathrm{AC}\right)$ composite photocatalysts were prepared by mixing $\mathrm{TiO}_{2}$ (Degussa P25) and activated carbon (AC) physically and via chemical integration of $\mathrm{TiO}_{2}$ and activated carbon (AC) starting with titanium tetraisopropoxide (TTIP) as titania source. In the formation of $\mathrm{TiO}_{2} / \mathrm{AC}$ composite physically, a method described elsewhere (Lee et al., 2004) was slightly modified and employed, for which desired amount of $\mathrm{TiO}_{2}$ nanoparticles (Degussa P25) was added to $100 \mathrm{ml}$ deionised water and stirred for $30 \mathrm{~min}$. An amount corresponded to 20 weight percent of activated carbon was added to the mixture and then agitated for another $1 \mathrm{~h}$, after which the mixture was then dried in a rotary evaporator and the composite made was labelled as $\mathrm{TiO}_{2} / \mathrm{AC} 1$.

However, in the chemical synthesis, the preparation procedure for the synthesis of $\mathrm{TiO}_{2} / \mathrm{AC}$ composite was applied as described in a related work (Torimoto et al., 1997). The $\mathrm{TiO}_{2}$ colloids were prepared by adding desired volume (corresponded to chosen weight percent) of titanium tetraisopropoxide drop-wisely to $50 \mathrm{ml}$ of $1 \mathrm{M} \mathrm{HNO}_{3}$ solution. The mixture was then agitated for $2 \mathrm{~h}$, which resulted in a transparent $\mathrm{TiO}_{2}$ sol that contained desired mass of $\mathrm{TiO}_{2}$. There 
was adjustment of $\mathrm{pH}$ of the transparent $\mathrm{TiO}_{2}$ sol with $1 \mathrm{M} \mathrm{NaOH}$ solution to $\mathrm{pH} 3$ after dilution with $250 \mathrm{ml}$ of deionised water, which resulted in the formation of turbid $\mathrm{TiO}_{2}$ colloid. To the colloid, desired amount (corresponded to 20 weight percent) of activated carbon was then added and stirred for another $1 \mathrm{~h}$ under room temperature, followed by several centrifugation and washings with distilled water until the $\mathrm{pH}$ of supernatant of the isolated $\mathrm{TiO}_{2} / \mathrm{AC}$ composite was neutral. The isolated $\mathrm{TiO}_{2} / \mathrm{AC}$ was dried under reduced pressure in a rotary evaporator. The obtained dried powder was subsequently calcined at $300{ }^{\circ} \mathrm{C}$ for $1 \mathrm{~h}$ and sample powdered composite labelled as $\mathrm{TiO}_{2} / \mathrm{AC} 2$. The pristine titania powder labelled as $\mathrm{TiO}_{2}-\mathrm{T}$ was synthesised by following the same protocols as described above with the omission of the activated carbon. It is worth to note that both in physical and chemical integration, 25, 50, and 75 weight percent activated carbon were also prepared, but herein reported only 20 weight percent as was found the optimal amount in the composites.

\subsection{Synthesis of $\mathrm{Cu}_{2} \mathrm{O} / \mathrm{TiO}_{2}$ and $\mathrm{Cu}_{2} \mathrm{O} / \mathrm{TiO}_{2}-\mathrm{AC}$ composite photocatalysts}

In the preparation of $\mathrm{Cu}_{2} \mathrm{O} / \mathrm{TiO}_{2}$, facile modified ethanol-induced reduction method as described by $\mathrm{Li}$ et al.(2015) was employed. Desired mass of $\mathrm{Cu}_{2} \mathrm{O} / \mathrm{TiO}_{2}$ was prepared by adding calculated amount of $\mathrm{Cu}\left(\mathrm{NO}_{3}\right)_{2} * 3 \mathrm{H}_{2} \mathrm{O}$ containing the desired weight percent of $\mathrm{Cu}$ into $200 \mathrm{ml}$ anhydrous ethanol suspension of $\mathrm{TiO}_{2}(\mathrm{P} 25)$ under continuous agitation. The mixture was stirred vigorously for $2 \mathrm{~h}$ and thereafter the solvent evaporated in an oven at $60{ }^{\circ} \mathrm{C}$ for $6 \mathrm{~h}$. The targeted material was obtained by calcining the solid product at $350{ }^{\circ} \mathrm{C}$ for $2 \mathrm{~h}$. The $\mathrm{Cu}_{2} \mathrm{O} / \mathrm{TiO}_{2}$ photocatalysts with different weight percent of $\mathrm{Cu}_{2} \mathrm{O}$ were obtained via repeating the above protocol by changing the content of $\mathrm{Cu}\left(\mathrm{NO}_{3}\right)_{2} * 3 \mathrm{H}_{2} \mathrm{O}$. The $\mathrm{Cu}_{2} \mathrm{O}$ weight percent loaded on $\mathrm{TiO}_{2}(\mathrm{P} 25)$ were determined from the $\mathrm{Cu}$ precursor based on the targeted total mass of the entire composites desired to acquire and recorded as $\mathrm{x} \% \mathrm{Cu} 2 \mathrm{O} / \mathrm{TiO}_{2}$, $\mathrm{x} \%$ referred to as weight percent $(\mathrm{wt} \%)$ of $\mathrm{Cu}_{2} \mathrm{O}$ in the composites. Similarly, various weight percent of $\mathrm{Cu}_{2} \mathrm{O}$ was also loaded on $\mathrm{TiO}_{2}-\mathrm{T}$ (Home-made) powder following the same procedure and the final solid products acquired labelled as $\mathrm{x} \% \mathrm{Cu}_{2} \mathrm{O} / \mathrm{TiO}_{2}-\mathrm{T}$. However, herein only 2.5 weight percent of $\mathrm{Cu}_{2} \mathrm{O}$ reported as was found the optimal amount in the composite.

In the preparation of carbon containing $\mathrm{Cu}_{2} \mathrm{O} / \mathrm{TiO}_{2}$, the same procedure was followed except $\mathrm{TiO}_{2}(\mathrm{P} 25)$ and $\mathrm{TiO}_{2}-\mathrm{T}$ were initially mixed with appropriate amount of activated carbon (AC) and stirred vigorously for an hour before the addition of desired amount of copper. The resulting solid composites were recorded as $\mathrm{x} \% \mathrm{Cu} 2 \mathrm{O} / \mathrm{TiO} 2-\mathrm{yAC}$, where $\mathrm{x} \%$ represents the determined optimum copper $\mathrm{wt} \%$ in $\mathrm{Cu}_{2} \mathrm{O} / \mathrm{TiO}_{2}$ and y equals to 20 weight percent of activated 
carbon in the composites. The two-acquired carbon containing $\mathrm{Cu}_{2} \mathrm{O} / \mathrm{TiO}_{2}$ composites synthesised from different titania sources were labelled as $2.5 \mathrm{Cu}_{2} \mathrm{O} / \mathrm{TiO}_{2}-20 \mathrm{AC}$ and 2.5 $\mathrm{Cu}_{2} \mathrm{O} / \mathrm{TiO}_{2}$ (T)-20AC for $\mathrm{P} 25$ and home-made titania, respectively.

\subsection{Adsorption tests of nitrate and oxalic acid}

The adsorption tests for single-component systems were conducted at constant temperature of $25 \pm 0.1{ }^{\circ} \mathrm{C}$ and without $\mathrm{pH}$ adjustment using different initial concentrations of nitrate and oxalic acid. $0.25 \mathrm{~g}$ of a sample under study was thoroughly mixed in a series of capped $100 \mathrm{ml}$ Pyrex bottles contained $25 \mathrm{ml}$ of nitrate or oxalic acid solutions with concentrations in the range $10-100 \mathrm{mg} / \mathrm{L}\left(1.61 \times 10^{-4}-1.61 \times 10^{-3} \mathrm{~mol} / \mathrm{L}\right)$ and $0.001,0.003$, $0.005,0.008$ and $0.010 \mathrm{~mol} / \mathrm{L}$, respectively, in a thermostat water bath/shaker for $24 \mathrm{~h}$. After the $24 \mathrm{~h}$ shaking, the suspensions were centrifuged, filtered with syringe filter $0.45 \mu \mathrm{m}$ (Millipore) and then analysed for equilibrium concentrations of nitrate and oxalic acid using UV-visible spectrophotometer (Lambda 25, PerkinElmer). For nitrate, spectrophotometric method was employed using nitrate test kit (Merck Spectroquant) for its residual concentration determinations, whereas oxalic acid was based on its characteristic functionality. To determine the uptake of nitrate and oxalic acid, the amount of nitrate and oxalic acid adsorbed per unit mass of sample (mol/g) was calculated using equation (1):

$\mathrm{q}_{\mathrm{e}}=\frac{\left(\mathrm{C}_{\mathrm{i}}-\mathrm{C}_{\mathrm{e}}\right)}{\mathrm{m}} \mathrm{V}$

where $\mathrm{q}_{\mathrm{e}}$ is the amount adsorbed at equilibrium $(\mathrm{mol} / \mathrm{g}), \mathrm{C}_{\mathrm{i}}$ is the initial concentration $(\mathrm{mol} / \mathrm{L})$, $\mathrm{C}_{\mathrm{e}}$ is the solution equilibrium concentration $(\mathrm{mol} / \mathrm{L}), \mathrm{V}$ is the volume of the aqueous phase (L), and $\mathrm{m}$ is the mass of the sample used.

\subsection{Simultaneous photocatalytic removal of nitrate and oxalic acid}

Photocatalytic reactions were carried out in a stirred, batch reactor fitted with a primary cooler (Fischer Scientific 3016S) to maintain the reaction temperature around $25 \pm 0.1^{\circ} \mathrm{C}$. A secondary cooling system was also incorporated to control heat given out by the UV lamp (Hereaus BQ $512 \mathrm{E}, 400 \mathrm{~W}, 230 \mathrm{~V}, 300 \mathrm{~nm} \leq \lambda \leq 800 \mathrm{~nm}$ ). Water was used as the coolant in this secondary cooling system by running a constant flow through a Pyrex cooler which encased the UV lamp. The temperature of the reactions was monitored by thermometer inserted in the reaction vessel. 
Initially, optimum amount of photocatalyst $(1.0 \mathrm{~g} / \mathrm{L})$ was suspended in $1.5 \mathrm{~L}$ of ultra-pure water fed into the reactor and then continuously stirred magnetically and bubbled $\mathrm{N}_{2}$ simultaneously to displace any dissolved oxygen present for 30 minutes. Thereafter, $100 \mathrm{ml}$ stock solution each of nitrate and oxalic acid were added to the suspension and gave rise to the total volume of $1.7 \mathrm{~L}$ containing concentrations of $100 \mathrm{ppm}(0.0016 \mathrm{~mol} / \mathrm{L})$ nitrate and 0.008 $/ 0.005 \mathrm{~mol} / \mathrm{L}$ oxalic acid. The content was further stirred for another $1 \mathrm{~h}$ in the dark, which was selected as the time required to attain adsorption-desorption equilibrium between the model pollutants and the solid. The light was then turned on after the initial sample was taken to determine the concentrations of the model pollutants in solution and considered as the initial concentrations. During the photocatalytic reaction test, samples were withdrawn at fixed time interval over a $3 \mathrm{~h}$ reaction period and filtered with a $0.45 \mu \mathrm{m}$ syringe filter before determination of nitrate and oxalic acid net concentrations, as well as the reaction products. The net concentrations of nitrate and oxalate as well as nitrite were measured using ion chromatography (IC-Dionex DX-120), while ammonium concentration was measured using a Merck Spectroquant ammonium test kit in a UV-visible spectrophotometer (Lambda 25, PerkinElmer). Thereafter, the degradation (\%) of both model pollutants was calculated using equation 2.

$$
\text { Degradation }(\%)=\frac{C_{t}}{C_{0}} \times 100
$$

where $\mathrm{C}_{0}$ stands for the initial concentration at zero time of illumination, $\mathrm{C}_{\mathrm{t}}$ is the concentration at a particular time of illumination. The selectivity toward $\mathrm{N}_{2}\left(\mathrm{~S}_{\mathrm{N} 2}\right), \mathrm{NO}_{2}{ }^{-}\left(\mathrm{S}_{\mathrm{NO}}{ }^{-}\right)$and $\mathrm{NH}_{4}{ }^{+}$ $\left(\mathrm{S}_{\mathrm{NH} 4}{ }^{+}\right)$were defined according to equation (3, 4 and 5).

$$
\begin{aligned}
& \mathrm{S}\left(\mathrm{NH}_{4}{ }^{+}\right)=\left[\mathrm{NH}_{4}{ }^{+}\right] \mathrm{t} /\left(\left[\mathrm{NO}_{3}{ }^{-}\right]_{0}-\left[\mathrm{NO}_{3}{ }^{-}\right] \mathrm{t}\right) \\
& \mathrm{S}\left(\mathrm{NO}_{2}^{-}\right)=\left[\mathrm{NO}_{2}{ }^{-}\right] \mathrm{t} /\left(\left[\mathrm{NO}_{3}{ }^{-}\right] 0-\left[\mathrm{NO}_{3}^{-}\right]_{\mathrm{t}}\right) \\
& \mathrm{S}(\mathrm{N} 2)=\left(\left[\mathrm{NO}_{3}{ }^{-}\right]_{0}-\left[\mathrm{NO}_{3}{ }^{-}\right]_{\mathrm{t}}-\left[\mathrm{NH}_{4}{ }^{+}\right]_{\mathrm{t}}-\left[\mathrm{NO}_{2}{ }^{-}\right]_{\mathrm{t}}\right) /\left(\left[\mathrm{NO}_{3}{ }^{-}\right]_{0}-\left[\mathrm{NO}_{3}{ }^{-}\right]_{\mathrm{t}}\right)
\end{aligned}
$$

where $[\mathrm{X}]_{0}$ is the concentration at time $=0$ and $[\mathrm{x}]_{\mathrm{t}}$ is the concentration at time $=\mathrm{t}$.

\subsection{Characterisation of the composite photocatalysts}

The X-ray diffraction pattern of the photocatalysts was examined using an X'Pert Pro Diffractometer (PANalytical) with a $\mathrm{Cu} \mathrm{K \alpha}$ radiation source $(\lambda=0.15418 \mathrm{~nm})$ in the range 5$80^{\circ} 2 \theta$. Textural properties (surface area, pore volume and pore size) were determined by 
collecting $\mathrm{N}_{2}$ adsorption-desorption isotherms at $-196^{\circ} \mathrm{C}$ on a Tristar-3000 instrument (Micromeritics). The optical properties of the photocatalysts were studied using a UV-Visible spectrometer (Cary 60, Perkin-Elmer) in diffuse reflectance mode using a $60 \mathrm{~mm}$ diameter integrated sphere and $\mathrm{BaSO}_{4}$ as the internal reference standard. To establish whether $\mathrm{Cu}$ influenced the band gap of $\mathrm{TiO}_{2}$ in the photocatalysts, plots of $(\alpha \mathrm{hv})^{1 / 2}$ versus $\mathrm{E}_{\text {photon was }}$ applied by fitting the absorption data to the equation. Reducibility of the photocatalysts was investigated by temperature-programmed reduction (TPR) using a TPDRO 1100 instrument equipped with a TCD detector. Samples were heated from 40 to $600^{\circ} \mathrm{C}$ at $5^{\circ} \mathrm{C} / \mathrm{min}$ in a $5 \%$ $\mathrm{H}_{2} / \mathrm{N}_{2}$ mixture. The amount of hydrogen consumed was quantified based on a response factor determined using a $\mathrm{CuO}$ reference standard. The oxidation state of $\mathrm{Cu}$ was probed by studying the adsorption of CO by FTIR (Perkin-Elmer 1750 series spectrometer). Sample was pressed into a self-supporting disc and held in a quartz holder in a vacuum line which allowed for heating, evacuation and gas manipulation. Samples were first outgassed and heated to $120^{\circ} \mathrm{C}$ to remove surface water. The sample was then cooled to room temperature and outgassed to a residual pressure of $c a .4 \times 10^{-5}$ Torr before an initial spectrum ( $25 \mathrm{scans}, 4 \mathrm{~cm}^{-1}$ resolution) was collected prior to exposure to increasing $\mathrm{CO}$ over-pressures $(0.2-50$ Torr $)$. Results are presented as difference spectra relative to the initial scan collected in the absence of CO. XPS measurements were carried out using a Kratos AXIS Ultra DLD XPS spectrometer with monochromated AlK $\alpha$ X-rays and hemispherical analyser with a pass energy of $160 \mathrm{eV}$. The powdered samples were mounted on copper tape and binding energies were normalised to the C 1s signal from adventitious carbon at $284.6 \mathrm{eV}$. Background subtraction was performed using a Shirley background and Casa XPS(Shirley, 1972).

\section{Results and discussion}

\subsection{Characterisation of the materials}

Activated carbon (AC) was used to modify the surface area of $\mathrm{TiO}_{2}$ to serve as an adsorbent as well as a photocatalyst for the simultaneous photocatalytic removal of nitrate and oxalic acids in aqueous environment. For this reason, raw activated carbon (AC) and the carbon-based composite photocatalysts were characterised using $\mathrm{N}_{2}$ gas adsorption-desorption experiments. The respective textural parameters of each of the material are tabulated in Table 1. From the results obtained, it is obvious that the textural parameters of the activated carbon and carbon-based $\mathrm{TiO}_{2}$ composite photocatalysts are significantly different from both unsupported titanium oxides. The result revealed that the surface area and pore volume of the 
carbon-based $\mathrm{TiO}_{2}$ composites are significantly greater than the unsupported titanium oxides, which may be of great importance to adsorption-photocatalysis hybrid system for the simultaneous removal of the model pollutants. On the other hand, for the carbon containing $\mathrm{Cu}_{2} \mathrm{O} / \mathrm{TiO}_{2}$ and $\mathrm{Cu}_{2} \mathrm{O} / \mathrm{TiO}_{2}-\mathrm{T}$ composites, the surface area of both titania decreased with addition of copper. However, incorporation of activated carbon into the composite at fixed copper loading $(2.5 \%)$ resulted in an increase in the surface area, particularly the surface area of copper-promoted $\mathrm{TiO}_{2}-\mathrm{P} 25$ changed by almost twofold (Table 1).

The isotherms of the $\mathrm{N}_{2}$ adsorption-desorption of some of the materials are presented in Fig. 1 and belong to type IV of the IUPAC classifications, as they evidently show openedlarge hysteresis loops (Sing, 1982) and also indicate the characteristics of mesoporous materials (Baek et al., 2013). The hysteresis loop of $\mathrm{TiO}_{2}-\mathrm{P} 25$ is more pronounced toward $\mathrm{P} / \mathrm{P}_{0}=1$, inferring the presence of large pores that are more open than the other materials (Table 1). This may be attributed to the effect of high calcination temperature imposed on the $\mathrm{TiO}_{2}-\mathrm{P} 25$ that was not applied on the other materials, since with an elevation of the calcination temperature, pore sizes increase and pore volumes decrease (Tryba et al., 2003). However, as can be seen from the isotherms, the immobilisation of the oxides unto the carbon body resulted in blockage of the porosity of the carbon support even though is mild and so noticeable in $\mathrm{TiO}_{2} / \mathrm{AC} 2$ and $\mathrm{TiO}_{2} / \mathrm{AC} 1$, respectively. Despite such, the materials retained porous character with relatively large surface area and pore volumes compared to both oxide photocatalysts (Fig. 1). The observed isotherms for the carbon-based composites are consistent with results in the literature (Gao et al., 2011; Tryba, 2008; Yu et al., 2003).

The corresponding pore size distribution profiles of the materials shown here are presented in Fig. 1b. The results of the pore size distribution are consistent with the $\mathrm{N}_{2}$ adsorption-desorption isotherms (Table 1), which also indicate the mesoporous nature of the materials, as all the pore size distributions are within the mesoporous classification $(2-50$ $\mathrm{nm})$. The trend also remained similar with respect to carbon containing $\mathrm{Cu}_{2} \mathrm{O} / \mathrm{TiO}_{2}$ composites. Interestingly, regarding the prepared composites, the portion of mesopores of $\mathrm{TiO}_{2} / \mathrm{AC} 2$ (Fig. 1b) was found to be even greater than the activated carbon (AC), which could be an advantage to adsorption-desorption processes on the surface of the composite. This marked difference in comparison with activated carbon may be attributed to the impact of the synthesis method, which perhaps also changed the morphology of the integrated activated carbon (AC), as the effect of preparatory method was also clearly manifested in the $\mathrm{TiO}_{2} / \mathrm{AC} 1$ composite. As shown in the pore size distribution profiles, after the impregnation of $\mathrm{TiO}_{2}$ on the activated carbon in the formation of $\mathrm{TiO}_{2} / \mathrm{AC} 1$ and $\mathrm{TiO}_{2} / \mathrm{AC} 2$, the pore volume of $\mathrm{AC}$ that is centred at 
$3.6 \mathrm{~nm}$ and larger than $5 \mathrm{~nm}$ decreased significantly and the decrease coincidently displayed the same declined shape in both composites, which may be the result of pore blockage by $\mathrm{TiO}_{2}$ particles (Fig. 1b). However, the pore volume of AC centred at $2.8 \mathrm{~nm}$ increased significantly in $\mathrm{TiO}_{2} / \mathrm{AC} 2$ and decreased for $\mathrm{TiO}_{2} / \mathrm{AC} 1$. The increase may be attributed to the cluster of mesopores in the $\mathrm{TiO}_{2}$ and partial blockage of the large pores by $\mathrm{TiO}_{2}$ particles ( $\mathrm{Yu}$ et al., 2003) whereas the decrease perhaps occurred because of the blockage of the mesopores of AC due to presence of $\mathrm{TiO}_{2}$ nanoparticles, which is also clearly observed in the $\mathrm{N}_{2}$ adsorptiondesorption isotherms (Fig. 1a). Severe pore blockage by $\mathrm{TiO}_{2}$ nanoparticles in the $\mathrm{TiO}_{2} / \mathrm{AC}$ composites may affect its adsorption properties. The modifications to the pore size distribution pattern here is similar with the trend reported by Gao et al. (2011) for $\mathrm{TiO}_{2} / \mathrm{AC}$ composite materials.

The XRD profiles of the $\mathrm{TiO}_{2}$ and their corresponding carbon-based composites are shown in Fig. 2a, which indicates that composites made up of $\mathrm{TiO}_{2}-\mathrm{P} 25$ contained two phases with the sharp peaks appearing at $25.3^{\circ}$ and $27.4^{\circ}$ characteristic of anatase and rutile revealed by index of ICDD-01-075-2550 and ICDD-01-001-1292, respectively. In contrast, samples of $\mathrm{TiO}_{2}-\mathrm{T}$ and its composite are mainly constituted by anatase crystallites. $\mathrm{The} \mathrm{Cu}_{2} \mathrm{O}$ phase was not detected in the photocatalytsts of $\mathrm{Cu}_{2} \mathrm{O} / \mathrm{TiO}_{2}$ and $\mathrm{Cu}_{2} \mathrm{O} / \mathrm{TiO}_{2}-\mathrm{T}$ and their corresponding carbon containing composites, which could be related to low content of copper loaded. The $\mathrm{UV}-\mathrm{Vis}$ diffuse reflectance of the both pure titania shown the characteristic absorption sharp edge rising at $400 \mathrm{~nm}$ as depicted in Fig. 2b. Conversely, all the composites shown absorption towards the visible light spectra range. This could be attributed to electronic transition involving $\mathrm{Cu}$ in the materials. In addition, amongst the carbon containing composites, 2.5 $\mathrm{Cu}_{2} \mathrm{O} / \mathrm{TiO}_{2}(\mathrm{~T})-20 \mathrm{AC}$ absorbed light at wavelength longer than its corresponding composite without activated carbon (Fig. 2b). This suggesting potential incorporated of carbon into the $\mathrm{TiO}_{2}$ structure apart from $\mathrm{Cu}$ and further revealed that activated carbon was integrated chemically and thus, is different from the physically formed composite $\left(2.5 \mathrm{Cu}_{2} \mathrm{O} / \mathrm{TiO}_{2}-20 \mathrm{AC}\right)$.

FTIR spectroscopy of adsorbed $\mathrm{CO}$ was employed to extract information regarding the oxidation state of $\mathrm{Cu}$. $\mathrm{CO}$ adsorbed onto exposed $\mathrm{Cu}^{2+}$ sites shows a band at $2200 \mathrm{~cm}^{-1}$ (Zhu et al., 2015) whereas peaks indicative of $\mathrm{Cu}^{+}$species and $\mathrm{Cu}^{0}$ appear at 2102-2133 and 2060$2080 \mathrm{~cm}^{-1}$, respectively (Boccuzzi et al., 1997; Coloma et al., 2001; Liu et al., 2012; Prestipino et al., 2006; Wu et al., 2011; Zhu et al., 2015). Figure 3a shows the spectra of adsorbed CO on $2.5 \mathrm{Cu}_{2} \mathrm{O} / \mathrm{TiO}_{2}$ sample. The main absorption band occurs at $2110 \mathrm{~cm}^{-1}$ and thus is attributed to adsorption on $\mathrm{Cu}^{+}$which is thought to be the main oxidation state. A small band is also observed at ca $2060 \mathrm{~cm}^{-1}$ and that confirms the presence of a small population of $\mathrm{Cu}^{0}$ sites. In 
contrast, sample of $2.5 \mathrm{Cu}_{2} \mathrm{O} / \mathrm{TiO}_{2}-\mathrm{T}$ photocatalyst did not adsorb $\mathrm{CO}$ to the same extent (Fig. $3 b$ ), with only a weak band observed at $c a .2115 \mathrm{~cm}^{-1}$ (ca. 60 folds less intense than observed for $2.5 \mathrm{Cu}_{2} \mathrm{O} / \mathrm{TiO}_{2}$ ). Note however that the absorption coefficient of $\mathrm{CO}$ on $\mathrm{Cu}^{+}$is known to be greater than for $\mathrm{CO}$ on $\mathrm{Cu}^{0}$ (Coloma et al., 2001), meaning that the $\mathrm{Cu}^{0}$ population is likely to be even lower than observed qualitatively. None of the samples exhibited a peak which can be assigned to $\mathrm{CO}$ adsorbed on $\mathrm{Cu}^{2+}$.

To evaluate the reducibility of copper species, $\mathrm{H}_{2}$-TPR profiles were collected (Fig. 4). The TPR profiles of both $2.5 \mathrm{Cu}_{2} \mathrm{O} / \mathrm{TiO}_{2}$ and $2.5 \mathrm{Cu}_{2} \mathrm{O} / \mathrm{TiO}_{2}-\mathrm{T}$ displayed a sharp reduction peak at $c a .160^{\circ} \mathrm{C}$, although both also gave another broad reduction peak at $c a .225^{\circ} \mathrm{C}$. Reduction of $\mathrm{Cu}^{+} \rightarrow \mathrm{Cu}^{0}$ must occur in a single step whereas reduction of $\mathrm{Cu}^{2+} \rightarrow \mathrm{Cu}^{0}$ can occur via a two-step process. However, no evidence of $\mathrm{C}^{2+}$ species was observed by FTIR of $\mathrm{CO}$. As such, the reduction peak at $c a .160^{\circ} \mathrm{C}$ is assigned to $\mathrm{Cu}_{2} \mathrm{O}$ species that are readily reduced due to their high dispersion on the support, while the additional peak centred at $c a$. $225^{\circ} \mathrm{C}$ for both samples could be related to reduction of $\mathrm{Cu}_{2} \mathrm{O}$ species that are weakly interacted with the support and/or with a larger particle size (Boccuzzi et al., 1997; Z. Wu et al., 2010). The percentage reduction was estimated from the consumption of hydrogen and the results obtained show that all the samples exhibited less than $50 \% \mathrm{Cu}$ reduction (based on $\mathrm{Cu}^{2+}$ as starting material) confirming the absence of $\mathrm{C} \mathrm{Cu}^{2+}$ species. All samples consume less hydrogen than required to stoichiometrically reduced $\mathrm{Cu}_{2} \mathrm{O}$, which suggests that at least some of the copper was likely in a reduced form - consistent with FTIR analysis. On this basis, this further suggesting that copper was appeared initially and predominantly as $\mathrm{Cu}_{2} \mathrm{O}$ in the samples.

In support of FTIR results, XPS analyses were conducted to gain insight into the nature of $\mathrm{Cu}$ ions in the two types of support. XPS spectra of $\mathrm{Cu} 2 \mathrm{p}$ core level profile of $2.5 \mathrm{Cu} 2 \mathrm{O} / \mathrm{TiO}_{2}$ is displayed in Fig. 3c. The $\mathrm{Cu} 2 \mathrm{p}_{3 / 2}$ characteristic peaks $\mathrm{Cu}^{0}, \mathrm{Cu}_{2} \mathrm{O}$, and $\mathrm{CuO}$ appear at 932, 932.7 and $933.6 \mathrm{eV}$ (Lalitha et al., 2010), respectively. However, in the $2.5 \% \mathrm{Cu}_{2} \mathrm{O} / \mathrm{TiO}_{2}$ apart from the $\mathrm{Cu} 2 \mathrm{p}_{3 / 2}$ and $2 \mathrm{p}_{1 / 2}$ characteristic peaks of $\mathrm{Cu}^{+}$, high energy satellite structures are found between 936 and $943 \mathrm{eV}$, which are associated with $\mathrm{Cu}^{2+}$ species. This weak satellite peak found in the samples of $2.5 \mathrm{Cu}_{2} \mathrm{O} / \mathrm{TiO}_{2}$ establishes that small quantities of $\mathrm{Cu}^{2+}$ were present as leftover, and thus confirmed that existed in the process of $\mathrm{Cu}_{2} \mathrm{O}$ nanoparticle formation on the surface of $\mathrm{TiO}_{2}$ and $\mathrm{TiO}_{2}-\mathrm{AC}$ supports.

\subsection{Adsorption isotherms of nitrate and oxalic acid}

Adsorption studies present parameters which provide information on the amount of adsorbate that can be taken up by an adsorbent. It has been long-established that adsorption 
studies describe the surface properties and affinity of adsorbent through an isotherm, which is essential in the interpretation and prediction of the magnitude of adsorption (LorencGrabowska and Gryglewicz, 2006; Vimonses et al., 2009). Furthermore, regarding heterogeneous photocatalytic reactions, fast rates of photodegradation of pollutants depends largely on the affinity of the reactants for the photocatalyst surface (Choi et al., 2014) and therefore, combining activated carbon (AC) and $\mathrm{TiO}_{2}$ could result in high concentrations of nitrate and oxalate in the proximity of the photocatalyst, which in effect could enhance the photodegradation of the model pollutants. Similarly, if oxalic acid is to provide electrons via oxidation by photogenerated holes on the surface of $\mathrm{TiO}_{2}$, which subsequently are to be used for the reduction of nitrates to maintain the neutrality of the $\mathrm{TiO}_{2}$ surface, then their adsorption on the surface of $\mathrm{TiO}_{2}$ is of paramount importance (Bems et al., 1999).

To establish the adsorption ability of the materials under study, the uptake as a function of equilibrium concentration on activated carbon (AC), $\mathrm{TiO}_{2} / \mathrm{AC} 1, \mathrm{TiO}_{2} / \mathrm{AC} 2, \mathrm{TiO}_{2}-\mathrm{T}$ and $\mathrm{TiO}_{2}-\mathrm{P} 25$ of nitrate and oxalic acid are presented in Fig. 5a and b, respectively. The amount adsorbed increased with an increase in oxalic acid or nitrate concentration and then consequently remained almost constant. This implies that saturation was attained, suggesting adsorption was limited to monolayer coverage of oxalic acid and nitrate. The materials offered different adsorption behaviour, among which activated carbon (AC) adsorbed greatest amount of either adsorbate when compared on a per gram basis. This was followed by $\mathrm{TiO}_{2} / \mathrm{AC} 2$ and then $\mathrm{TiO}_{2} / \mathrm{AC} 1$. Conversely, the titanium dioxides adsorbed nearly the same and different amounts of oxalic acid and nitrate, respectively. This trend of the adsorption ability is consistent with the textural characteristics, such as surface areas, of the materials (Table 1). However, it is worth mentioning that mixing $\mathrm{TiO}_{2}$ with activated carbon (AC) brought about an improvement in the adsorption ability of both commercially and laboratory based $\mathrm{TiO}_{2}$. The composites were superior in their adsorption ability in comparison to both titania. The adsorption behaviour exhibited by activated carbon (AC) and the composites towards oxalic acid, as an organic substance is similar to previous works (Andreina, 2010; Ao et al., 2008; Matos et al., 2010; Matos et al., 2010), which could be attributed to large surface area of AC as well as its co-adsorbent effect that improved the adsorption ability of $\mathrm{TiO}_{2}$ through surface functional groups.

In support of the above discussion, it has been established that activated carbon is an excellent adsorbent for the removal of wide range of aqueous pollutants particularly organics ones. However, it is a poor adsorbent for the adsorption of anionic pollutants and thus, this may be responsible for low volume of studies reporting adsorption of $\mathrm{NO}_{3}{ }^{-}$by activated carbon 
(Bhatnagar and Sillanpää, 2011). The effects of functional groups on the adsorption of $\mathrm{NO}_{3}^{-}$ and $\mathrm{NO}_{2}^{-}$by carbon cloth was investigated and the results revealed that carbon cloth treated with acid formed positive sites on the material due to protonation of its surface $\mathrm{OH}^{-}$groups that caused an increase in electrostatic adsorption of the anions. The dramatic improvement in the adsorption was attributed to the electrostatic interaction between the anions and positively charged sites on the surface of the acid-treated carbon cloth, as the distilled water-treated carbon cloth adsorbed 5 and 20 times less of $\mathrm{NO}_{3}{ }^{-}$and $\mathrm{NO}_{2}{ }^{-}$, respectively, compared to the former (Afkhami et al., 2007). In a very recently reported work, a similar scenario was also observed where $\mathrm{NO}_{3}{ }^{-}$adsorption was enhanced due to involvement of the surface $\mathrm{OH}^{-}$groups by bridging between $\mathrm{NO}_{3}{ }^{-}$and metal oxide surfaces (Suriyaraj et al., 2015). Therefore, as revealed from the literature, the high uptake of oxalic acid than nitrate by carbon based $\mathrm{TiO}_{2}$, i.e. $\mathrm{TiO}_{2} / \mathrm{AC} 1$ and $\mathrm{TiO}_{2} / \mathrm{AC} 2$ could also be held by the above observations. Because the ionic form of oxalic acid in a solution of $\mathrm{pH} 1.5$ to 3.9 is mainly $\mathrm{HC}_{2} \mathrm{O}_{4}^{-}$(Janusz and Matysek, 2006) and therefore, as the adsorption measurement was carried out within this range, the adsorption of oxalic acid over the composites should be more than that of nitrate due to electrostatic interaction between $\mathrm{HC}_{2} \mathrm{O}_{4}{ }^{-}$and positively charged surface sites of the composites. A similar observation was made where initial $\mathrm{pH}$ can increase the adsorption of a catalytic substrate on the phtotocatalyst and thus, can increase the efficiency of photocatalysis (He et al., 2010).

Langmuir and Freundlich isotherm models were used to gain further understanding and description of the adsorption behaviour of the materials. According to the quality of the fit, the adsorption data for both oxalic acid and nitrate are best described by the Langmuir model with a correlation coefficient $\left(\mathrm{R}^{2}>0.99\right)$ higher than that obtained with Freundlich $\left(\mathrm{R}^{2}<0.73\right)$. This revealed that the equilibrium data for adsorption of nitrate and oxalic acid for all the materials agreed best with the Langmuir equation (Fig. 5c and d, respectively). The uptake and derived Langmuir constants are shown in Table 2. Interestingly, the Langmuir constant for oxalic acid on $\mathrm{TiO}_{2}-\mathrm{P} 25$ and $\mathrm{AC}$ were fairly similar, and this was also the case for nitrate on the two reference samples. The relative strength of adsorption of nitrate was increased on both composites with respect to the references while oxalic acid adsorption strength was diminished for the composite prepared by physical mixture $\left(\mathrm{TiO}_{2} / \mathrm{AC} 1\right)$, but enhanced for the chemically combined composite $\left(\mathrm{TiO}_{2} / \mathrm{AC} 2\right)$. From the results, in all cases the Langmuir constants for nitrate are higher than those of the oxalic acid, suggesting greater affinity for this adsorbate than oxalic acid for all the materials despite that was adsorbed to a lesser extent. A similar observation has been reported for $\mathrm{TiO}_{2}-\mathrm{P} 25$ sample ( $\mathrm{Li}$ and Wasgestian, 1998). This difference between the amount of uptake and strength of adsorption could arise from the ability of oxalic 
acid to bind via its two adsorption modes, which may involve both two carbonyl groups or one carbonyl and one hydroxyl groups (Fahmi et al., 1995). Therefore, it could be inferred that oxalic acid has a greater number of options in terms of adsorption sites than nitrate does, even though nitrate too could bind $\mathrm{TiO}_{2}$ in either monodentate or bidentate configuration (Hadjiivanov et al., 1994). Nevertheless, the amounts of both oxalic acid and nitrate adsorbed were significantly increased by the addition of activated carbon (AC) to the $\mathrm{TiO}_{2}$ when considered based on per unit mass (Table 2), which is far above the capacity of $\mathrm{TiO}_{2}$ alone. This is consistent with a report in the literature that activated carbon can be a co-adsorbent to enhance the adsorption capacity of $\mathrm{TiO}_{2}$ (Yu et al., 2005). Similarly, in terms of affinity for the model pollutants the adsorption strength of nitrate was increased on both composites when compared with the reference materials- $\mathrm{TiO}_{2}-\mathrm{P} 25, \mathrm{TiO}_{2}-\mathrm{T}$ and activated carbon (AC). Conversely, in the case of oxalic acid, the increment was only observed on the chemically combined composite $\left(\mathrm{TiO}_{2} / \mathrm{AC} 2\right)$. This disparity may be associated with their textural characteristics, which perhaps originated from different preparatory methods.

\subsection{Photocatalytic removal of nitrate and oxalic acid}

The photocatalytic performance profile of $\mathrm{TiO}_{2}-\mathrm{P} 25, \mathrm{TiO}_{2}-\mathrm{T}$, and $\mathrm{TiO}_{2} / \mathrm{AC}$ composites in the simultaneous photocatalytic remediation of nitrate and oxalic acid is presented in Fig. 6. Under the experimental conditions employed, none of the materials used showed any photocatalytic activity in the reduction of nitrate. The result was not entirely unexpected given that previous reports have shown that $\mathrm{TiO}_{2}$ alone is either inactive(Bems et al., 1999; Gao et al., 2004; Jin et al., 2004) or slightly active(Ren et al., 2015; Rengaraj and Li, 2007) or very active.(Sá et al., 2009). Thus, the discrepancies between the reported data regarding the activity of $\mathrm{TiO}_{2}$ seems difficult to resolve, but may be largely attributed to the operational factors since performance is known to depend heavily on conditions employed(Jin et al., 2004) and/or seems to depend on the type of organic hole scavenger employed(Gao et al., 2004; Jin et al., 2004; Sá et al., 2009). This was also the same case for the composites prepared here which can be related directly to the inactivity of $\mathrm{TiO}_{2}$ in the photocatalytic reduction of nitrate. However, the materials exhibited activity in the degradation of oxalic acid and their rate constants (Table 3) for removal were quite similar for both the reference $\mathrm{TiO}_{2}$ and $\mathrm{TiO}_{2} / \mathrm{AC} 2$ but almost an order of magnitude less for $\mathrm{TiO}_{2} / \mathrm{AC} 1$. While this may be in some way related to the characteristics of this sample that led to it displaying the lowest Langmuir constant (for oxalic acid), but the highest for nitrate amongst the samples described here (Table 2). This difference did not induce improved performance in terms of nitrate reduction. 
However, with integration of $\mathrm{Cu}_{2} \mathrm{O}$ into the $\mathrm{TiO}_{2}-20 \mathrm{AC}$, the simultaneous photocatalytic removal of nitrate and oxalic acid was successfully occurred. Therefore, the addition of $\mathrm{Cu}_{2} \mathrm{O}$ activated the photocatalytic potential of $\mathrm{TiO}_{2}$ for the reduction of nitrate, presumably via effective charge carrier separation. On the other hand, $\mathrm{Cu}$ and $\mathrm{Cu}^{+}$are also active and easily be oxidized in reducing nitrate. This perhaps connected to the fact that $\mathrm{Cu}_{2} \mathrm{O}$ has poor stability in aqueous solutions, because the redox potentials for the reduction and oxidation of monovalent copper oxide lie within the bandgap (Paracchino et al., 2011) and thus, is quite a limiting factor for its photocatalytic application in aqueous solutions. However, combining $\mathrm{Cu}_{2} \mathrm{O}$ with $\mathrm{TiO}_{2}$ is a potential solution to the problem of $\mathrm{Cu}_{2} \mathrm{O}$ instability in water under illumination. This is because $\mathrm{TiO}_{2}$ served as a protective n-type oxide, whose conduction band lies in between the $\mathrm{Cu}_{2} \mathrm{O}$ conduction band and therefore, assisted in extracting photogenerated electrons from $\mathrm{Cu}_{2} \mathrm{O}$ leading to enhance the stability of $\mathrm{Cu}_{2} \mathrm{O}$ in water under illumination (i.e., avoiding the occurrence of reduction of $\mathrm{Cu}_{2} \mathrm{O}$ to $\mathrm{Cu}$ ). $\mathrm{As}^{\mathrm{TiO}_{2}}$ is an n-type with valence band edge of $2.9 \mathrm{~V}$ coupled with p-type $\mathrm{Cu}_{2} \mathrm{O}$ semiconductor with an appropriate conduction band edge of $-1.64 \mathrm{~V}$ (Wang et al., 2013), photogenerated electrons can be transferred from the conduction band of $\mathrm{Cu}_{2} \mathrm{O}$ to $\mathrm{TiO}_{2}$ and holes migrate from the valence band of $\mathrm{TiO}_{2}$ to $\mathrm{Cu}_{2} \mathrm{O}$ and thus, electron-hole transfer between the heterojunction is thermodynamically permitted. This served as an effective way of retarding electron-hole recombination and eventually resulted in the simultaneous photocatalytic degradation of nitrate and oxalic acid over the sample. In addition, the presence of activated carbon in the sample enhanced photocatalytic degradation of the pollutants via increased adsorption capacity and improved interfacial charge transfer rate. Conversely, the reduction reaction carried out with $\mathrm{Cu}_{2} \mathrm{O}$ promoted $\mathrm{TiO}_{2}-(\mathrm{T})-20 \mathrm{AC}$ composite, where less than $50 \%$ of oxalic acid removed and no nitrate reduction was observed. The photocatalytic reduction non-performance of $\mathrm{Cu}_{2} \mathrm{O}$ promoted $\mathrm{TiO}_{2}-(\mathrm{T})$ and its carbon-based composite (Fig. 7a and b) may be connected to crystallinity of the titania produced, as it mainly in amorphous phase (Fig. 2a) and perhaps served as charge carrier trapping sites that hindered activity. Fig. 7c and d show the photocatalytic performance of $\mathrm{Cu}_{2} \mathrm{O}$ promoted $\mathrm{TiO}_{2}$ and their carbon-based composites. The results reveal that the combination of $2.5 \mathrm{Cu}_{2} \mathrm{O} / \mathrm{TiO}_{2}$ with activated carbon (AC) clearly resulted in a decrease in the removal rates of nitrate and oxalic acid rates (Table 4). The effect was so conspicuous, where the rates sharply declined by greater than 6 and 2 times less than the rates of removal of nitrate and oxalic acid, respectively compared to $2.5 \mathrm{Cu} 2 \mathrm{O} / \mathrm{TiO}_{2}$ photocatalytic performance (Table 4 and Fig. 7b). This may be attributed to light shielding effect imposed by AC in the composite, which perhaps prevented UV light from reaching the 
light harvesting centres where the reactions occur on the surface of the photocatalyst. This phenomenon was also observed elsewhere(Gao et al., 2011; Wei et al., 2014). Besides, the UV-vis spectra of the composite with AC loading absorbed light lower than that of 2.5 $\mathrm{Cu}_{2} \mathrm{O} / \mathrm{TiO}_{2}$ (Fig. 2b), which could further explain the decrease in conversion rate of the carbonbased $2.5 \mathrm{Cu}_{2} \mathrm{O} / \mathrm{TiO}_{2}$. The maximum conversion of nitrate was $57.6 \%$ with a selectivity to $\mathrm{N}_{2}$ of $41.9 \%$ and an oxalic acid conversion of $99.8 \%$ after $3 \mathrm{~h}$ reaction using $2.5 \mathrm{Cu} 2 \mathrm{O} / \mathrm{TiO}_{2}$, but its carbon-based form recorded further increased selectivity to $\mathrm{N}_{2}$ with drastic decrease in selectivity for ammonium and nitrite down to 21.6 and $0 \%$, respectively (Table 4). This indicates that the reaction products selectivity seems to be governed by the sluggish conversion rate of oxalic acid. Therefore, the presence of $\mathrm{AC}$ in $\mathrm{Cu}_{2} \mathrm{O} / \mathrm{TiO}_{2}$ was found to be detrimental to rate, but advantageous to $\mathrm{N}_{2}$ selectivity.

\section{Conclusion}

The $\mathrm{TiO}_{2} / \mathrm{AC}$ composites photocatalysts were successfully prepared through physical and chemical integration protocols. Adsorption isotherms were carried out with the aim to evaluate their adsorption capacity alongside with the reference materials, which are $\mathrm{TiO}_{2}-\mathrm{P} 25, \mathrm{TiO}_{2}-\mathrm{T}$ and activated carbon (AC). From the adsorption isotherm measurements, although uptake of both nitrate and oxalic acid was improved compared to pure titanium oxides, but oxalic acid was adsorbed more than the nitrate despite its low adsorption constant relative to nitrate. Among the findings, in terms of adsorption capacity, $\mathrm{TiO}_{2} / \mathrm{AC} 2$ adsorbed more of the model pollutants than $\mathrm{TiO}_{2} / \mathrm{AC} 1$ and both composites did not provide adsorption additive effect after mixing the two solids. Nevertheless, combining $\mathrm{TiO}_{2}$ with activated carbon resulted in improvement in the adsorption uptake of both nitrate and oxalic acid.

Similarly, adsorption-photocatalytic hybrid investigations were also carried out over the materials and found that both the reference titanium oxides and their corresponding carbonbased composites yielded no photocatalytic reduction of nitrate. Therefore, it appeared that enhancing capacity using $\mathrm{TiO}_{2} / \mathrm{AC}$ composites did not appear to produce more active photocatalysts for the simultaneous degradation of nitrate/oxalic acid, but this conceivably related directly to the fact that even $\mathrm{TiO}_{2}$, as the basic photocatalyst, did not show any photocatalytic activity for nitrate reduction. With such observation, this study further explored the potentiality of copper in the composites by synthesising $\mathrm{Cu}_{2} \mathrm{O}$ promoted titania and their corresponding carbon-based composites. The materials of $\mathrm{Cu}_{2} \mathrm{O} / \mathrm{TiO}_{2}, \mathrm{Cu}_{2} \mathrm{O} / \mathrm{TiO}_{2}-\mathrm{T}$ and their carbon-based photocatalyst composites were synthesised by a facile ethanol reduction method. The results of XRD, $\mathrm{H}_{2}$-TPR and FTIR of adsorbed $\mathrm{CO}$ indicate that $\mathrm{Cu}_{2} \mathrm{O}$ nanoparticles were 
formed and coupled with $\mathrm{TiO}_{2}$. Interestingly, with addition of $\mathrm{Cu}_{2} \mathrm{O}$ into the $\mathrm{TiO}_{2}$ and $\mathrm{TiO}_{2}-$ $20 \mathrm{AC}$, the simultaneous photocatalytic removal of nitrate and oxalic acid was successfully occurred. Both types of the photocatalysts showed activity in the simultaneous photocatalytic removal of nitrate and oxalic acid. The $2.5 \mathrm{Cu}_{2} \mathrm{O} / \mathrm{TiO}_{2}$ exhibited the maximum photocatalytic performance with 57.6 and $99.8 \%$ removal of nitrate and oxalic acid, respectively, but with selectivities of $45.7,12.4$ and $41.9 \%$ for $\mathrm{NH}_{4}{ }^{+}, \mathrm{NO}_{2}{ }^{-}$and $\mathrm{N}_{2}$, respectively. However, for the carbon containing photocatalyst with optimal carbon loading (i.e., $2.5 \mathrm{Cu}_{2} \mathrm{O} / \mathrm{TiO}_{2}-20 \mathrm{AC}$ ) displayed the highest conversion in the same reaction with 12.7 and $80.3 \%$ removal of nitrate and oxalic acid, respectively and yielded $78.4 \%$ selectivity $\mathrm{N}_{2}$ while that of $\mathrm{NH}_{4}{ }^{+}$and $\mathrm{NO}_{2}{ }^{-}$ drastically dropped to 21.6 and $0 \%$, respectively. Although enhancing capacity through composites based on $\mathrm{TiO}_{2} /$ activated carbons did not appear to produce more active photocatalysts for the simultaneous degradation of nitrate/oxalic acid, but accordingly this study reveals that selectivity for desired product appeared to be governed by the rate of conversion of oxalic acid and therefore selectivity for $\mathrm{N}_{2}$ can be manipulated by controlling the rate of consumption of oxalic acid. On the other hand, less than $50 \%$ of oxalic acid removed and no nitrate reduction was observed in the photocatalytic reduction reaction carried out with $\mathrm{Cu}_{2} \mathrm{O}$ promoted $\mathrm{TiO}_{2}-\mathrm{T}$ and its $\mathrm{TiO}_{2}-(\mathrm{T})-20 \mathrm{AC}$ composite. This non-performance of $\mathrm{Cu}_{2} \mathrm{O}$ promoted $\mathrm{TiO}_{2}-(\mathrm{T})$ and its carbon-based composite may be connected to crystallinity of the titania produced, as it mainly be made up of amorphous phase and perhaps served as charge carrier trapping sites that impeded activity. Besides, the FTIR of adsorbed CO further support that difference between the two materials implies that participation of a surface $\mathrm{Cu}$ species is vital for photo-reduction of nitrate. Although photocatalytic reduction of nitrate was not achieved with the prepared $\mathrm{Cu}_{2} \mathrm{O} / \mathrm{TiO}_{2}-\mathrm{T}$ and its carbon containing composite, however, measurement of adsorption uptake data and photocatalytic reaction data can allow an understanding of the parameters which may be key in trying to develop improved photocatalysts

\section{Conflicts of interest}

There are no conflicts of interest to declare with regards to this research work.

\section{Acknowledgement}

We are sincerely grateful to Petroleum Technology Development Fund, Nigeria (PTDF) for the financial provision made available for this research work under the auspices of 
overseas scholarship scheme (OSS). Similarly, special thanks to Abubakar Tafawa Balewa University, Bauchi-Nigeria for the award of fellowship to Haruna Adamu.

\section{References}

Afkhami, A., Madrakian, T., Karimi, Z. (2007). The effect of acid treatment of carbon cloth on the adsorption of nitrite and nitrate ions. Journal of Hazardous Materials, 144(1-2), 427431. doi:http://dx.doi.org/10.1016/j.jhazmat.2006.10.062

Anderson, J. A. (2012). Simultaneous photocatalytic degradation of nitrate and oxalic acid over gold promoted titania. Catalysis Today, 181(1), 171-176.

Anderson, J. A., Fernandez-Garcia, M. (2009). Catalytic and photocatalytic removal of pollutants from aqueous sources. Catalysis, 21, 51-81.

Andreina Garcia, J. M. (2010). Photocatalytic activity of $\mathrm{TiO}_{2}$ on activated carbon under visible light in the photodegradation of phenol. Open Materials Science Journal, 4, 2-4.

Ao, Y., Xu, J., Fu, D., Shen, X., Yuan, C. (2008). Low temperature preparation of anatase TiO2-coated activated carbon. Colloids and Surfaces A: Physicochemical and Engineering Aspects, 312(2-3), 125-130.

Baek, M., Jung, W., Yoon, J., Hong, J., Lee, Y., Suh, J. (2013). Preparation, characterization and photocatalytic activity evaluation of micro- and mesoporous $\mathrm{TiO}_{2} /$ spherical activated carbon. Journal of Industrial and Engineering Chemistry, 19(2), 469-477. doi:http://dx.doi.org/10.1016/j.jiec.2012.08.026

Beltrán, F. J., Rivas, F. J., Montero-de-Espinosa, R. (2005). Iron type catalysts for the ozonation of oxalic acid in water. Water Research, 39(15), 3553-3564.

Bems, B., Jentoft, F. C., Schlögl, R. (1999). Photoinduced decomposition of nitrate in drinking water in the presence of titania and humic acids. Applied Catalysis B: Environmental, 20(2), 155-163.

Bhatnagar, A., Sillanpää, M. (2011). A review of emerging adsorbents for nitrate removal from water. Chemical Engineering Journal, 168(2), 493-504. doi:http://dx.doi.org/10.1016/j.cej.2011.01.103

Boccuzzi, F., Chiorino, A., Martra, G., Gargano, M., Ravasio, N., Carrozzini, B. (1997). Preparation, characterization, and activity of $\mathrm{cu} / \mathrm{TiO} 2$ catalysts: I. influence of the preparation method on the dispersion of copper in $\mathrm{cu} / \mathrm{TiO}_{2}$. Journal of Catalysis, 165(2), 129-139.

Choi, J., Lee, H., Choi, Y., Kim, S., Lee, S., Lee, S., Lee, J. (2014). Heterogeneous photocatalytic treatment of pharmaceutical micropollutants: Effects of wastewater effluent 
matrix and catalyst modifications. Applied Catalysis B: Environmental, 147(0), 8-16. doi:http://dx.doi.org/10.1016/j.apcatb.2013.08.032

Coloma, F., Bachiller-Baeza, B., Rochester, C. H., Anderson, J. A. (2001). Infrared study of competitive crotonaldehyde and $\mathrm{CO}$ adsorption on $\mathrm{Cu} / \mathrm{TiO}_{2}$. Physical Chemistry Chemical Physics, 3(21), 4817-4825. doi:10.1039/b106244c

Fahmi, A., Minot, C., Fourré, P., Nortier, P. (1995). A theoretical study of the adsorption of oxalic acid on $\mathrm{TiO}_{2}$. Surface Science, 343(3), 261-272. doi:http://dx.doi.org/10.1016/0039-6028(95)00813-6

Gao, B., Yap, P. S., Lim, T. M., Lim, T. (2011). Adsorption-photocatalytic degradation of acid red 88 by supported $\mathrm{TiO}_{2}$ : Effect of activated carbon support and aqueous anions. Chemical Engineering Journal, 171, 1098-1107.

Gao, W., Jin, R., Chen, J., Guan, X., Zeng, H., Zhang, F., Guan, N. (2004). Titania-supported bimetallic catalysts for photocatalytic reduction of nitrate. Catalysis Today, 90(3-4), 331336. doi:http://dx.doi.org/10.1016/j.cattod.2004.04.043

Hadjiivanov, K., Bushev, V., Kantcheva, M., Klissurski, D. (1994). Infrared spectroscopy study of the species arising during $\mathrm{NO}_{2}$ adsorption on $\mathrm{TiO}_{2}$ (anatase). Langmuir, 10(2), 464-471.

$\mathrm{He}, \mathrm{H}$. (2016). Facile synthesis of ultrafine $\mathrm{CuS}$ nanocrystalline/ $\mathrm{TiO}_{2}$ : Fe nanotubes hybrids and their photocatalytic and fenton-like photocatalytic activities in the dye degradation. Microporous and Mesoporous Materials, 227, 31-38.

He, H., Huang, J., Cao, L., Wu, J. (2010). Photodegradation of methyl orange aqueous on $\mathrm{MnWO}_{4}$ powder under different light resources and initial $\mathrm{pH}$. Desalination, 252(1-3), 6670.

Hirayama, J., Kamiya, Y. (2014). Combining the photocatalyst $\mathrm{Pt} / \mathrm{TiO}_{2}$ and the nonphotocatalyst $\mathrm{SnPd} / \mathrm{Al}_{2} \mathrm{O}_{3}$ for effective photocatalytic purification of groundwater polluted with nitrate. ACS Catalysis, 4(7), 2207-2215.

Janusz, W., Matysek, M. (2006). Co-adsorption of $\mathrm{Cd}(\mathrm{II})$ and oxalate ions at the $\mathrm{TiO}_{2} /$ electrolyte solution interface. Journal of Colloid and Interface Science, 296(1), 2229. doi:http://dx.doi.org/10.1016/j.jcis.2005.08.067

Jin, R., Gao, W., Chen, J., Zeng, H., Zhang, F., Liu, Z., Guan, N. (2004). Photocatalytic reduction of nitrate ion drinking water by using metal-loaded $\mathrm{MgTiO}_{3}-\mathrm{TiO}_{2}$ composite semiconductor catalyst. Journal of Photochemistry and Photobiology A: Chemistry, 162(2-3), 585-590.

Lalitha, K., Sadanandam, G., Kumari, V. D., Subrahmanyam, M., Sreedhar, B., \& Hebalkar, N. Y. (2010). Highly stabilized and finely dispersed $\mathrm{Cu}_{2} \mathrm{O} / \mathrm{TiO}_{2}$ : A promising visible 
sensitive photocatalyst for continuous production of hydrogen from glycerol: Water mixtures. The Journal of Physical Chemistry C, 114(50), 22181-22189.

Lee, D. K., Kim, S. C., Cho, I. C., Kim, S. J., Kim, S. W. (2004). Photocatalytic oxidation of microcystin-LR in a fluidized bed reactor having $\mathrm{TiO}_{2}$-coated activated carbon. Sep. Purif. Technol., 34, 59-66.

Li, L., Xu, Z., Liu, F., Shao, Y., Wang, J., Wan, H., \& Zheng, S. (2010). Photocatalytic nitrate reduction over $\mathrm{Pt}-\mathrm{Cu} / \mathrm{TiO}_{2}$ catalysts with benzene as hole scavenger. Journal of Photochemistry and Photobiology A: Chemistry, 212(2-3), 113-121. doi:http://dx.doi.org/10.1016/j.jphotochem.2010.04.003

Li, Y., Wang, B., Liu, S., Duan, X., Hu, Z. (2015). Synthesis and characterization of $\mathrm{Cu}_{2} \mathrm{O} / \mathrm{TiO}_{2}$ photocatalysts for $\mathrm{H}_{2}$ evolution from aqueous solution with different scavengers. Applied Surface Science, 324, 736-744. doi:10.1016/j.apsusc.2014.11.027

Li, Y., Wasgestian, F. (1998). Photocatalytic reduction of nitrate ions on $\mathrm{TiO}_{2}$ by oxalic acid. Journal of Photochemistry and Photobiology A: Chemistry, 112(2-3), 255-259. doi:http://dx.doi.org/10.1016/S1010-6030(97)00293-1

Lim, T., Yap, P., Srinivasan, M., Fane, A. G. (2011). $\mathrm{TiO}_{2} / \mathrm{AC}$ composites for synergistic adsorption-photocatalysis processes: Present challenges and further developments for water treatment and reclamation. Critical Reviews in Environmental Science and Technology, 41(13), 1173-1230.

Liu, L., Zhao, C., Li, Y. (2012). Spontaneous dissociation of $\mathrm{CO}_{2}$ to $\mathrm{CO}$ on defective surface of $\mathrm{Cu}(\mathrm{I}) / \mathrm{TiO}_{2}-\mathrm{x}$ nanoparticles at room temperature. Journal of Physical Chemistry C, 116(14), 7904-7912. doi:10.1021/jp300932b

Lorenc-Grabowska, E., Gryglewicz, G. (2006). Adsorption characteristics of congo red on coal-based mesoporous activated carbon. Dyes and Pigments, 74(1), 34-40.

Matos, J., Laine, J., Hermann, J. (1998). Synergy effect in the photocatalytic degradation of phenol on a suspended mixture of titania and activated carbon. Appl. Catal. B: Environ., 18, 281-291.

Matos, J., Laine, J., Herrmann, J. (2001). Effect of the type of activated carbons on the photocatalytic degradation of aqueous organic pollutants by UV-irradiated titania. Journal of Catalysis, 200(1), 10-20.

Matos, J., Laine, J., Herrmann, J., Uzcategui, D., Brito, J. (2007). Influence of activated carbon upon titania on aqueous photocatalytic consecutive runs of phenol photodegradation. Applied Catalysis B: Environmental, 70(1), 461-469. 
Matos, J., Garcia, A., Chovelon, J., Ferronato, C. (2010). Combination of adsorption on activated carbon and oxidative photocatalysis on $\mathrm{TiO}_{2}$ for gaseous toluene remediation. Open Materials Science Journal, 4, 23-25.

Matos, J., García-López, E., Palmisano, L., García, A., Marcì, G. (2010). Influence of activated carbon in $\mathrm{TiO}_{2}$ and $\mathrm{ZnO}$ mediated photo-assisted degradation of 2-propanol in gas-solid regime. Applied Catalysis B: Environmental, 99(1-2), 170-180.

Paracchino, A., Laporte, V., Sivula, K., Grätzel, M., Thimsen, E. (2011). Highly active oxide photocathode for photoelectrochemical water reduction. Nature Materials, 10(6), 456.

Pinheiro, G. K., Serpa, R. B., de Souza, L. V., Sartorelli, M. L., Reis, F. T., Rambo, C. R. (2017). Increasing incident photon to current efficiency of perovskite solar cells through $\mathrm{TiO}_{2}$ aerogel-based nanostructured layers. Colloids and Surfaces A: Physicochemical and Engineering Aspects, 527, 89-94.

Prestipino, C., Regli, L., Vitillo, J. G., Bonino, F., Damin, A., Lamberti, C., Bordiga, S. (2006). Local structure of framework $\mathrm{Cu}(\mathrm{II})$ in HKUST-1 metallo-organic framework: Spectroscopic characterization upon activation and interaction with adsorbates. Chemistry of Materials, 18(5), 1337-1346. doi:10.1021/cm052191g

Ren, H., Jia, S., Zou, J., Wu, S., Han, X. (2015). A facile preparation of Ag2O/P25 photocatalyst for selective reduction of nitrate. Applied Catalysis B: Environmental, 176177, 53-61. doi:http://dx.doi.org/10.1016/j.apcatb.2015.03.038

Rengaraj, S., Li, X. Z. (2007). Enhanced photocatalytic reduction reaction over $\mathrm{Bi}^{3+}-\mathrm{TiO}_{2}$ nanoparticles in presence of formic acid as a hole scavenger. Chemosphere, 66(5), 930938. doi:http://dx.doi.org/10.1016/j.chemosphere.2006.06.007

Sá, J., Agüera, C. A., Gross, S., Anderson, J. A. (2009). Photocatalytic nitrate reduction over metal modified TiO2. Applied Catalysis B: Environmental, 85(3-4), 192-200. doi:http://dx.doi.org/10.1016/j.apcatb.2008.07.014

Saeed, M., Ilyas, M., Siddique, M., Ahmad, A. (2013). Oxidative degradation of oxalic acid in aqueous medium using manganese oxide as catalyst at ambient temperature and pressure. Arabian Journal for Science and Engineering, 38(7), 1739-1748. doi:10.1007/s13369013-0545-x

Shand, M., Anderson, J. A. (2013). Aqueous phase photocatalytic nitrate destruction using titania based materials: Routes to enhanced performance and prospects for visible light activation. Catalysis Science and Technology, 3(4), 879-899.

Shirley, D. A. (1972). High-resolution X-ray photoemission spectrum of the valence bands of gold. Physical Review B, 5(12), 4709. 
Sing, K. S. W. (1982). Reporting physisorption data for gas/solid systems with special reference to the determination of surface area and porosity. Pure and Appl. Chem., 54, 2201-2218.

Suriyaraj, S., Pillai, M. M., Bhattacharyya, A., Selvakumar, R. (2015). Scavenging of nitrate ions from water using hybrid $\mathrm{Al}_{2} \mathrm{O}_{3} /$ bio- $\mathrm{TiO}_{2}$ nanocomposite impregnated thermoplastic polyurethane nanofibrous membrane. RSC Advances, 5(84), 68420-68429.

Torimoto, T., Okawa, Y., Takeda, N., Yoneyama, H. (1997). Effect of activated carbon content in $\mathrm{TiO}_{2}$-loaded activated carbon on photodegradation behaviours of dichloromethane. Journal of Photochemistry and Photobiology A: Chemistry, 103(1-2), 153-157.

Tryba, B. (2008). Increase of the photocatalytic activity of $\mathrm{TiO}_{2}$ by carbon and iron modifications. International Journal of Photoenergy, 2008

Tryba, B., Morawski, A. W., \& Inagaki, M. (2003). Application of $\mathrm{TiO}_{2}$-mounted activated carbon to the removal of phenol from water. Applied Catalysis B: Environmental, 41(4), 427-433.

Vimonses, V., Lei, S., Jin, B., Chow, C. W. K., Saint, C. (2009). Kinetic study and equilibrium isotherm analysis of congo red adsorption by clay materials. Chemical Engineering Journal, 148(2-3), 354-364.

Wakida, F. T., Lerner, D. N. (2005). Non-agricultural sources of groundwater nitrate: A review and case study. Water Research, 39(1), 3-16. doi:10.1016/j.watres.2004.07.026

Wang, Z., Liu, Y., Martin, D. J., Wang, W., Tang, J., Huang, W. (2013). CuO x-TiO 2 junction: What is the active component for photocatalytic $\mathrm{H}_{2}$ production. Physical Chemistry Chemical Physics, 15(36), 14956-14960.

Wei, W., Yu, C., Zhao, Q., Qian, X., Li, G., Wan, Y. (2014). Synergy effect in photodegradation of contaminants from water using ordered mesoporous carbon-based titania catalyst. Applied Catalysis B: Environmental, 146, 151-161.

Wu, G., Guan, N., Li, L. (2011). Low temperature $\mathrm{CO}$ oxidation on $\mathrm{Cu}-\mathrm{Cu}_{2} \mathrm{O} / \mathrm{TiO}_{2}$ catalyst prepared by photodeposition. Catalysis Science and Technology, 1(4), 601-608. doi:10.1039/c1cy00036e

Wu, Z., Zhu, H., Qin, Z., Wang, H., Huang, L., Wang, J. (2010). Preferential oxidation of CO in $\mathrm{H}_{2}$-rich stream over $\mathrm{CuO} / \mathrm{Ce}_{1-x} \mathrm{Ti}_{\mathrm{x}} \mathrm{O}_{2}$ catalysts. Applied Catalysis B: Environmental, 98(3-4), 204-212. doi:http://dx.doi.org/10.1016/j.apcatb.2010.05.030

Yang, R., Cai, J., Lv, K., Wu, X., Wang, W., Xu, Z., Xu, W. (2017). Fabrication of $\mathrm{TiO}_{2}$ hollow microspheres assembly from nanosheets ( $\left.\mathrm{TiO}_{2}-\mathrm{HMSs}-\mathrm{NSs}\right)$ with enhanced photoelectric conversion efficiency in DSSCs and photocatalytic activity. Applied Catalysis B: Environmental, 210, 184-193. 
Yu, J., Yu, J. C., Leung, M. K. -., Ho, W., Cheng, B., Zhao, X., Zhao, J. (2003). Effects of acidic and basic hydrolysis catalysts on the photocatalytic activity and microstructures of bimodal mesoporous titania. Journal of Catalysis, 217(1), 69-78. doi:http://dx.doi.org/10.1016/S0021-9517(03)00034-4

Yu, Y., Yu, J. C., Chan, C., Che, Y., Zhao, J., Ding, L., Wong, P. (2005). Enhancement of adsorption and photocatalytic activity of $\mathrm{TiO}_{2}$ by using carbon nanotubes for the treatment of azo dye. Applied Catalysis B: Environmental, 61(1-2), 1-11. doi:http://dx.doi.org/10.1016/j.apcatb.2005.03.008

Zhu, S., Liang, S., Tong, Y., An, X., Long, J., Fu, X., Wang, X. (2015). Photocatalytic reduction of $\mathrm{CO}_{2}$ with $\mathrm{H}_{2} \mathrm{O}$ to $\mathrm{CH}_{4}$ on $\mathrm{Cu}(\mathrm{I})$ supported $\mathrm{TiO}_{2}$ nanosheets with defective $\{001\}$ facets. Physical Chemistry Chemical Physics, 17(15), 9761-9770. doi: $10.1039 / \mathrm{c} 5 \mathrm{cp} 00647 \mathrm{c}$

Table 1. Textural properties of materials.

\begin{tabular}{lccc}
\hline Materials & $\mathrm{S}_{\mathrm{BET}}\left(\mathrm{m}^{2} \mathrm{~g}^{-1}\right)$ & Average Pore size $(\mathrm{nm})$ & Pore volume $\left(\mathrm{cm}^{3} \mathrm{~g}^{-1}\right)$ \\
\hline $\mathrm{TiO}_{2}-\mathrm{P} 25$ & 54 & 15.5 & 0.25 \\
$\mathrm{TiO}_{2}-\mathrm{T}$ & 177 & 4.7 & 0.26 \\
$\mathrm{AC}$ & 1280 & 6.6 & 0.76 \\
$\mathrm{TiO}_{2} / \mathrm{AC} 1$ & 699 & 8.2 & 0.59 \\
$\mathrm{TiO}_{2} / \mathrm{AC} 2$ & 880 & 4.4 & 0.63 \\
$2.5 \mathrm{Cu}_{2} \mathrm{O} / \mathrm{TiO}_{2}$ & 50 & 26.7 & 0.38 \\
$2.5 \mathrm{Cu}_{2} \mathrm{O} / \mathrm{TiO}_{2}-\mathrm{T}$ & 169 & 3.8 & 0.15 \\
$2.5 \mathrm{Cu}_{2} \mathrm{O} / \mathrm{TiO}_{2}-20 \mathrm{AC}$ & 96 & 19.3 & 0.38 \\
$2.5 \mathrm{Cu}_{2} \mathrm{O} / \mathrm{TiO}_{2}(\mathrm{~T})-20 \mathrm{AC}$ & 192 & 3.3 & 0.13 \\
\hline
\end{tabular}


Table 2. Adsorption parameters related to oxalic acid and nitrate uptakes on samples at $25^{\circ} \mathrm{C}$ and extracted by fitting to the Langmuir equation.

\begin{tabular}{llllll}
\hline Materials & $\begin{array}{l}\mathrm{S}_{\mathrm{BET}} \\
\left(\mathrm{m}^{2} \mathrm{~g}^{-1}\right)\end{array}$ & $\begin{array}{l}\mathrm{q}_{\mathrm{e}}(\mathrm{mol} / \mathrm{g}) \\
(\text { Nitrate })\end{array}$ & $\mathrm{K}_{\mathrm{L}}\left(\mathrm{M}^{-1}\right)$ & $\begin{array}{l}\mathrm{q}_{\mathrm{e}}(\mathrm{mol} / \mathrm{g}) \\
(\text { Oxalic acid })\end{array}$ & $\mathrm{K}_{\mathrm{L}}\left(\mathrm{M}^{-1}\right)$ \\
\hline $\mathrm{TiO}_{2}-\mathrm{P} 25$ & 54 & $8.38 \times 10^{-5}$ & 4672 & $8.20 \times 10^{-4}$ & 1137 \\
$\mathrm{TiO}_{2}-\mathrm{T}$ & 177 & $3.60 \times 10^{-5}$ & 2218 & $8.82 \times 10^{-4}$ & 1168 \\
$\mathrm{AC}$ & 1280 & $3.01 \times 10^{-4}$ & 4290 & $1.76 \times 10^{-3}$ & 1102 \\
$\mathrm{TiO}_{2} / \mathrm{AC} 1$ & 699 & $1.19 \times 10^{-4}$ & 6175 & $1.05 \times 10^{-3}$ & 976 \\
$\mathrm{TiO}_{2} / \mathrm{AC} 2$ & 880 & $1.34 \times 10^{-4}$ & 5763 & $1.21 \times 10^{-3}$ & 2086 \\
\hline
\end{tabular}

Table 3. Rate constants for removal of oxalic acid at $25^{\circ} \mathrm{C}$.

\begin{tabular}{ll}
\hline Materials & $\begin{array}{l}\text { Rate constant } \\
\left(\mathrm{min}^{-1}\right)\end{array}$ \\
\hline $\mathrm{TiO}_{2}-\mathrm{P} 25$ & $1.41 \times 10^{-2}$ \\
$\mathrm{TiO}_{2}-\mathrm{T}$ & $1.27 \times 10^{-2}$ \\
$\mathrm{TiO}_{2} / \mathrm{AC} 1$ & $2.30 \times 10^{-3}$ \\
$\mathrm{TiO}_{2} / \mathrm{AC} 2$ & $1.33 \times 10^{-2}$ \\
$\mathrm{AC}$ & $2.12 \times 10^{-3}$ \\
\hline
\end{tabular}

Table 4. Conversion, rate constants (k), selectivity of $\mathrm{NH} 4+$, NO2- and $\mathrm{N} 2$ for $\mathrm{Cu} 2 \mathrm{O} / \mathrm{TiO} 2$ and their carbon-based composite photocatalysts.

\begin{tabular}{|c|c|c|c|c|c|c|c|}
\hline \multirow[t]{2}{*}{ Materials } & \multirow{2}{*}{$\begin{array}{c}\text { Nitrate } \\
\text { conversion } \\
(\%)\end{array}$} & \multirow{2}{*}{$\begin{array}{l}\text { Oxalate } \\
\text { conversion } \\
(\%)\end{array}$} & \multicolumn{2}{|c|}{$\begin{array}{l}\text { Rate constant } \\
\qquad\left(\mathrm{min}^{-1}\right)\end{array}$} & \multirow{2}{*}{$\begin{array}{c}\mathrm{NH}^{+} \\
\text {selectivity } \\
(\%)\end{array}$} & \multirow{2}{*}{$\begin{array}{c}\mathrm{NO}_{2}^{-} \\
\text {selectivity } \\
(\%)\end{array}$} & \multirow{2}{*}{$\begin{array}{c}\mathrm{N}_{2} \\
\text { selectivity } \\
(\%)\end{array}$} \\
\hline & & & Nitrate & Oxalate & & & \\
\hline $2.5 \mathrm{Cu}_{2} \mathrm{O} / \mathrm{TiO}_{2}-\mathrm{T}$ & 0 & 34.7 & 0 & 0.0049 & 0 & 0 & 0 \\
\hline $2.5 \mathrm{Cu}_{2} \mathrm{O} / \mathrm{TiO}_{2}-(\mathrm{T})-20 \mathrm{AC}$ & 0 & 41.1 & 0 & 0.0063 & 0 & 0 & 0 \\
\hline $2.5 \mathrm{Cu}_{2} \mathrm{O} / \mathrm{TiO}_{2}$ & 57.6 & 99.8 & 0.0058 & 0.0166 & 45.7 & 12.4 & 41.9 \\
\hline $2.5 \mathrm{Cu}_{2} \mathrm{O} / \mathrm{TiO}_{2}-20 \mathrm{AC}$ & 12.7 & 80.3 & 0.0009 & 0.008 & 21.6 & 0 & 78.4 \\
\hline
\end{tabular}



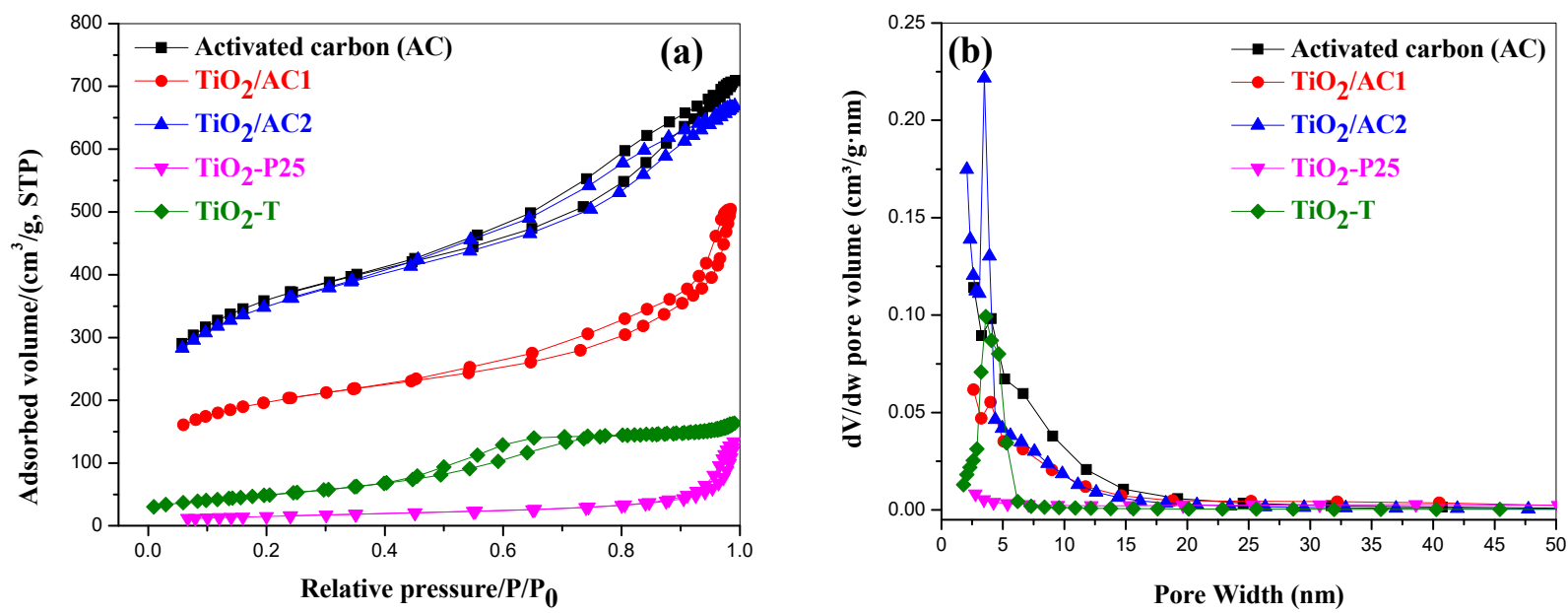

Figure 1- (a) $\mathrm{N}_{2}$ adsorption-desorption isotherms of samples, (b) Pore size distributions of some of the materials.
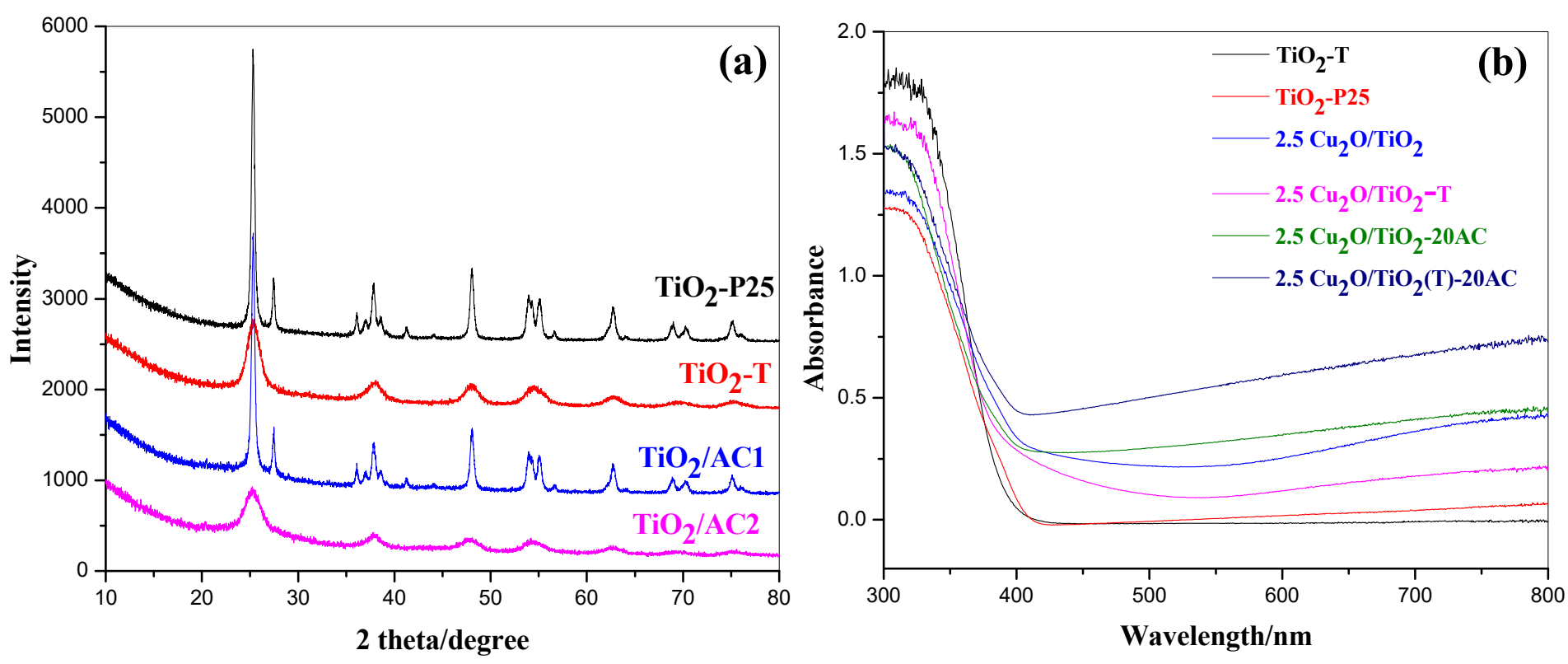

Figure 2 - (a) X-ray diffraction patterns of $\mathrm{TiO}_{2}$ and composite photocatalysts, (b)UVvis diffuse reflectance of $\mathrm{TiO}_{2}$, composites and their copper based photocatalysts. 

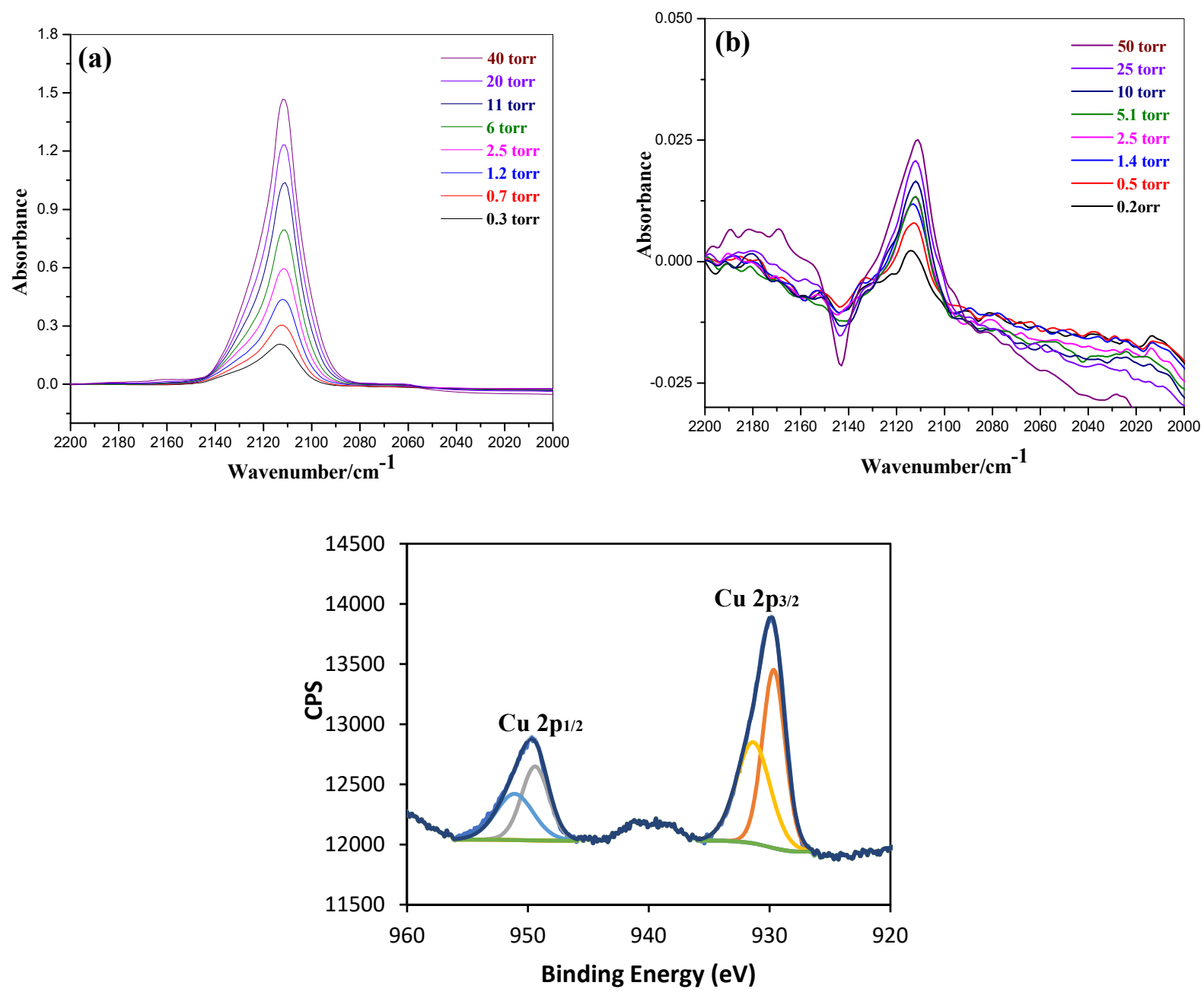

Figure 3 - FTIR spectra of $\mathrm{CO}$ adsorbed on (a) $2.5 \mathrm{Cu}_{2} \mathrm{O} / \mathrm{TiO}_{2}$, (b) $2.5 \mathrm{Cu}_{2} \mathrm{O} / \mathrm{TiO}_{2}$-T, (c) XPS Spectra of $\mathrm{Cu}_{2} \mathrm{O} / \mathrm{TiO}_{2}$.

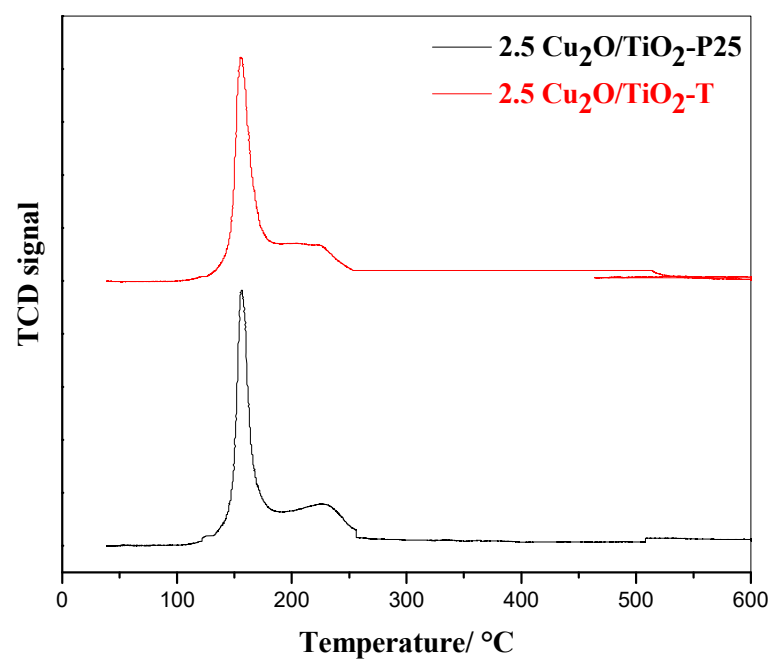

Figure 4 - TPR profiles of $2.5 \mathrm{Cu}_{2} \mathrm{O} / \mathrm{TiO}_{2}$, and $2.5 \mathrm{Cu}_{2} \mathrm{O} / \mathrm{TiO}_{2}-\mathrm{T}$. 

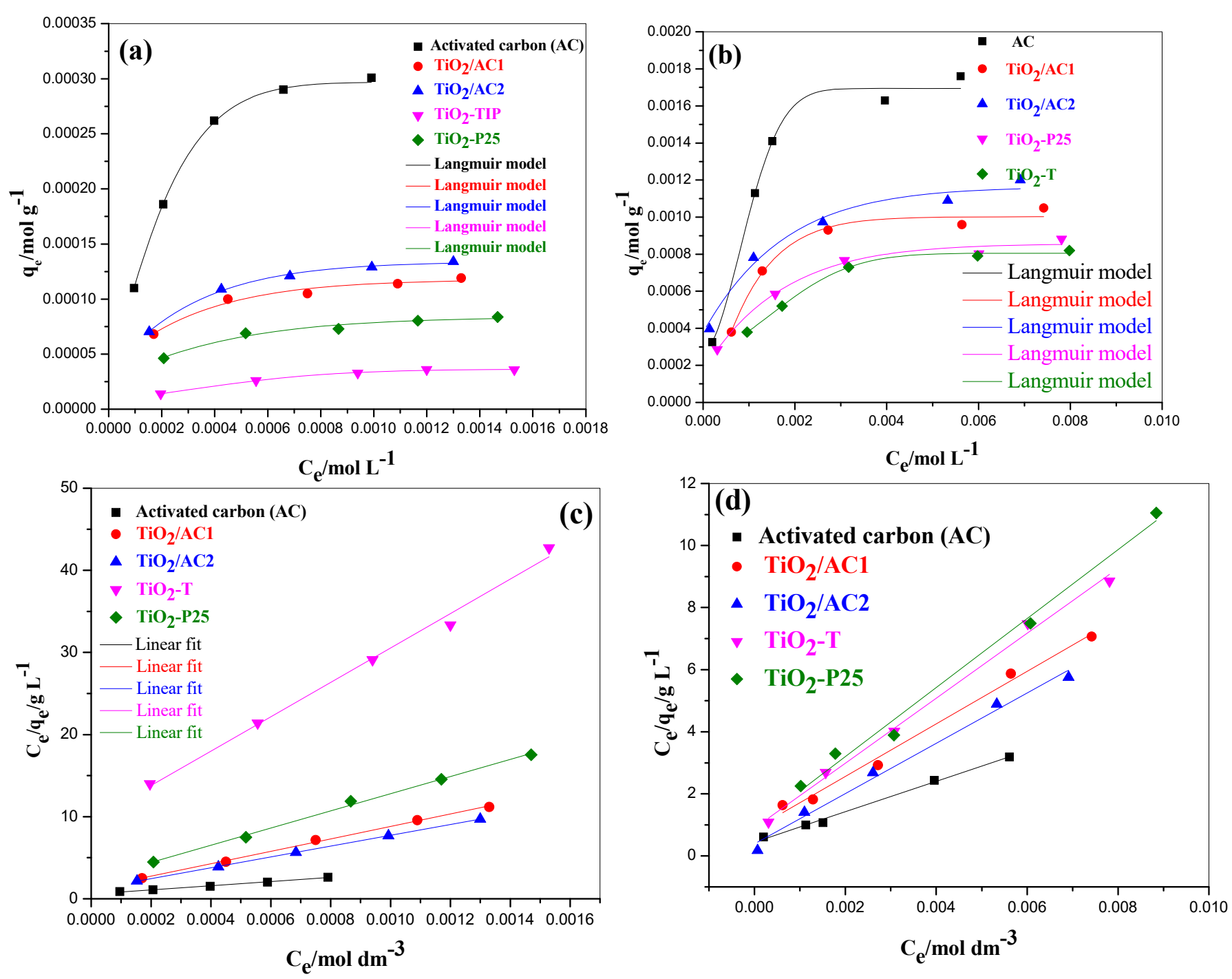

Figure 5- (a) adsorption isotherm for nitrate, (b) for oxalic acid;

Langmuir expression (c) for nitrate adsorption isotherm and (d) for oxalic acid adsorption isotherm. 

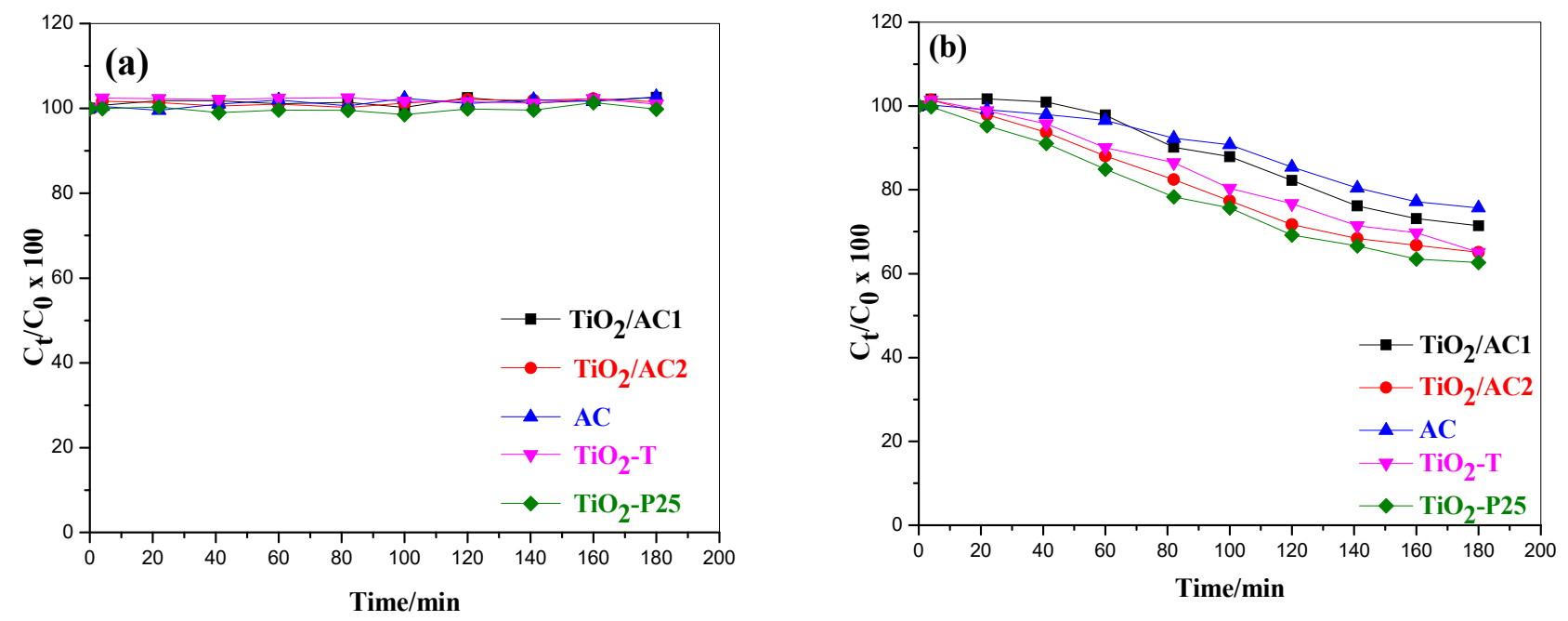

Figure 6- (a) Simultaneous photocatalytic removal of nitrate, (b) of oxalic acid.
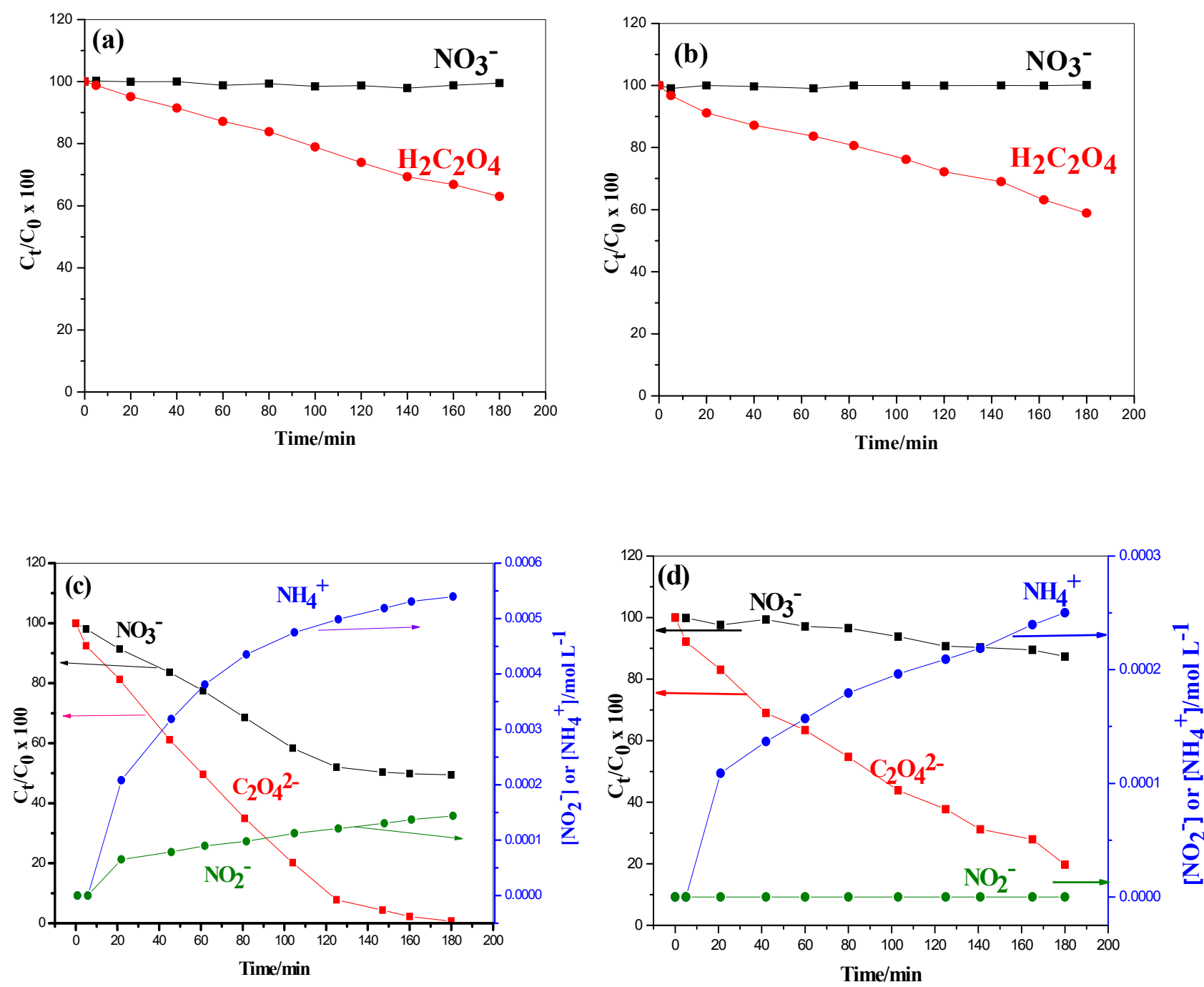

Figure 7 - Simultaneous photocatalytic remediation of nitrate and oxalic acid by (a) 2.5 $\mathrm{Cu}_{2} \mathrm{O} / \mathrm{TiO}_{2}-\mathrm{T}$, (b) $2.5 \mathrm{Cu}_{2} \mathrm{O} / \mathrm{TiO}_{2}$ (T)-20AC, (c) $2.5 \mathrm{Cu}_{2} \mathrm{O} / \mathrm{TiO}_{2}$, and (d) $2.5 \mathrm{Cu}_{2} \mathrm{O} / \mathrm{TiO}_{2}$ 20AC. 